\title{
Study of the Thermal Field Upstream and Downstream of Two Heat Sources Placed in the Turbulent Flow of the Ambient Air Cooled through an Air-Ground Heat Exchanger
}

B. S. Tagne-Kaptue ${ }^{1}$, Oumarou Hamandjoda ${ }^{1}$, B. Kenmeugne ${ }^{1}$, J. Kenfack, A. Kanmogne ${ }^{1}$, L. Meva’a ${ }^{1}$ and D. Ndapeu $^{2}$

1. Department of Mechanical and Industrial Engineering, ENSP, University of Yaoundé I, P.O. Box 8390, Yaoundé, Cameroon

2. Department of Mechanical and Production Engineering, University Institute, Fotso Victor, Bandjoun, University of Dschang, P.O.

Box 134, Bandjoun, Koung Khi, Cameroon

\begin{abstract}
In order to more easily highlight the influence of cooled ambient air through an air-ground heat exchanger on the process of diffusion and mixing of heat around an electronic component and a photovoltaic solar module, we undertook to study the thermal field beforehand. The turbulent model has applied a realizable $\mathrm{k}-\varepsilon$ two equations model and the two-dimensional Reynolds Averaged Navier-Stokes (RANS) equations are discretized with the second order upwind scheme. The SIMPLE algorithm, which is developed using control volumes, is adopted as the numerical procedure. Calculations were performed for a wide variation of the Reynolds numbers. Our results reveal, on the one hand, that the use of an air-ground heat exchanger accelerates the dispersion of the thermal field around the PV panel. On the other hand, with increasing Reynolds number, the instabilities appear in the wake zone, showing an oscillatory flow, also called von Karman Vortex Street. Our air-ground heat exchanger has an important influence on the diffusion process of the thermal field. Comparison of numerical results with the experimental data available in the literature is satisfactory.
\end{abstract}

Key words: Passive scalar, linear heat source, PV module, turbulent flow, CFD.

\section{Nomenclature}

Small Letters

a Thermal diffusivity

d Diameter of the source line

$\mathrm{x} \quad$ Longitudinal coordinates

y Vertical coordinate

z Transverse coordinate

h Enthalpy mass

$t$ time

$\mathrm{u}, \mathrm{v}, \mathrm{w} \quad$ Components of speed

$\Delta \mathrm{x} \quad$ Dimension of a control volume following " $\mathrm{x}$ "

$\Delta y \quad$ Dimension of a control volume

following " $y$ "

$\dot{m} \quad$ Mass flow rate of air

$h \quad$ Convection coefficient

Corresponding author: B. S. Tagne-Kaptue.

\section{Capital Letters}

$\mathrm{m}^{2} \cdot \mathrm{s}^{-1}$

$\mathrm{m} \quad \mathrm{D}$

m $\quad H$

$\mathrm{m} \quad \mathrm{L}_{\mathrm{f}}$

$\mathrm{m} \quad \mathrm{C}_{\mathrm{P}}$

$\mathrm{J} \cdot \mathrm{kg}^{-1} \quad \mathrm{U}_{\mathrm{f}}$

$\mathrm{S}$

$\mathrm{m} \cdot \mathrm{s}^{-1}$

$\mathrm{m}$

$\mathrm{m}$

$\mathrm{kg} \cdot \mathrm{K}^{-1}$

$\mathrm{W} \cdot \mathrm{m}^{-2}$

Thickness of the air layer in collector $\mathrm{PV} / \mathrm{T}$

Diameter of the main cylinder m

Relative height of the pipe $\mathrm{m}$

Characteristic length of the fluid $\mathrm{m}$

Thermal capacity at constant pressure $\mathrm{J} \cdot \mathrm{kg}^{-1} \cdot \mathrm{K}^{-1}$

$\mathrm{U}_{\mathrm{f}} \quad$ Speed of flowing air $\mathrm{m}$

$\mathrm{L} \quad$ Length of the collector m

$\mathrm{T}_{\mathrm{Pv}} \quad \mathrm{PV}$ cell temperature $\quad \mathrm{K}$

$\mathrm{T}_{\mathrm{f}} \quad$ Fluid temperature (air) $\mathrm{K}$

$\mathrm{T}_{\mathrm{a}} \quad$ Ambient temperature $\mathrm{K}$

$\mathrm{T}_{\text {isol }} \quad$ Temperature of the insulation $\mathrm{K}$

$\mathrm{T}_{\mathrm{fb}} \quad$ Temperature of the enclosed air loop $\mathrm{K}$

$\mathrm{T}_{\text {as }} \quad$ Ambient temperature $\mathrm{K}$

$\mathrm{T}_{\text {ciel }} \quad$ Temperature of the sky $\mathrm{K}$

$\mathrm{P} \quad$ Pressure $\mathrm{Pa}$

$\mathrm{T}$ temperature difference $\mathrm{K}$ 


\section{Turbulent Flow of the Ambient Air Cooled through an Air-Ground Heat Exchanger}

$\begin{array}{lll}\Delta \mathrm{T}_{\text {réf }} & \begin{array}{l}\text { Temperature difference between the hot } \\ \text { jet and the outside }\end{array} \\ \mathrm{U}_{\propto} & \begin{array}{l}\text { Velocity of the flow upstream of the } \\ \text { main cylinder }\end{array} & \mathrm{m} \cdot \mathrm{s}^{-1} \\ \mathrm{U}_{\mathrm{j}} & \text { Air outlet speed } & \mathrm{m} \cdot \mathrm{s}^{-1} \\ \mathrm{U}_{\mathrm{f}} & \text { Speed characteristic of the fluid } & \mathrm{m} \cdot \mathrm{s}^{-1} \\ 0 \mathrm{x} & \text { Longitudinal axis } & \mathrm{m} \\ 0 \mathrm{y} & \text { Vertical axis } & \mathrm{m} \\ 0 \mathrm{z} & \text { Transverse axis } & \mathrm{m}\end{array}$

\section{Greek Symbols}

\begin{tabular}{|c|c|}
\hline$v$ & Kinematic viscosity of the air \\
\hline$\mu$ & Dynamic viscosity of the air \\
\hline$\varepsilon$ & $\begin{array}{l}\text { Rate of dissipation of turbulent kinetic } \\
\text { energy }\end{array}$ \\
\hline K & Turbulent kinetic energy \\
\hline$\rho$ & Density \\
\hline$\eta_{e l}$ & Electrical efficiency of the collector \\
\hline$\eta_{t h}$ & Thermal efficiency of the collector \\
\hline$\varnothing$ & Density of radiation flux \\
\hline$\Psi$ & Collector width \\
\hline$\Theta$ & Angle of inclination \\
\hline A & Absorption coefficient \\
\hline $\mathrm{a}$ & Thermal diffusivity \\
\hline$\lambda$ & Coefficient of conduction of heat \\
\hline
\end{tabular}

Non-dimensional Numbers

$\begin{array}{ll}\mathrm{U}, \mathrm{V} & \begin{array}{l}\text { Components of the dimensionless } \\ \text { velocity }\end{array} \\ \mathrm{Ra} & \text { Number of Rayleigh } \\ \mathrm{Re} & \text { Number of Reynolds } \\ \mathrm{Re}_{\mathrm{s}} & \text { Reynolds number of linear source } \\ \mathrm{Gr}_{\mathrm{s}} & \text { Grashof number of the linear source } \\ \mathrm{Gr} & \text { Number of grashof } \\ \mathrm{Pr} & \text { Number of turbulent Prandtl } \\ \mathrm{St} & \text { Number of Strouhal } \\ \sigma_{\mathrm{k}} \text { and } \sigma_{\varepsilon} & \text { Number of turbulent Prandtl relative to } \\ \mathrm{k} \text { and } \varepsilon\end{array}$

\section{Exhibitors, Indices and Special Characters}

\begin{tabular}{|c|c|}
\hline $\mathrm{C}$ & Critical \\
\hline $\mathrm{n}+1$ & $\begin{array}{l}\text { Iteration counter corresponding to the } \\
\text { time at } t+\Delta t\end{array}$ \\
\hline S & Linear heat source \\
\hline el & El ectric \\
\hline th & Thermal \\
\hline ext & Outside \\
\hline int & inside \\
\hline Isol & Insulating \\
\hline V & Glass \\
\hline $\mathrm{C}$ & convection \\
\hline
\end{tabular}

$\begin{array}{ll}\mathrm{r} & \text { radiation } \\ \text { as } & \text { Ambient } \\ \mathrm{Sol} & \text { Ground } \\ \mathrm{Av} & \text { Before } \\ \mathrm{Ap} & \text { After } \\ \mathrm{b} & \text { Air blade enclosed } \\ \mathrm{sV} & \text { Under vacuum } \\ \mathrm{F} & \text { Coolant } \\ \mathrm{S}_{\mathrm{ij}} & \text { Average stress tensor } \\ \mu_{\mathrm{t}} & \text { Turbulent kinematic viscosity } \\ \mathrm{D}_{\mathrm{t}} & \text { Turbulent dynamic viscosity } \\ v_{\mathrm{ref}} & \text { Viscosity dynamic turbulence reference } \\ \varepsilon_{\mathrm{ijk}} & \text { Trace along direction k of flow } \\ \check{\mathrm{S}} & \text { Average of Favre of the tensor stress } \\ \mathrm{K}_{\mathrm{eff}} & \text { ratio } \\ \mathrm{K} & \text { Effective thermal conductivity } \\ \sigma_{\mathrm{ij}} & \text { Thermal conductivity } \\ \left(\tau_{\mathrm{ij}}\right)_{\text {eff }} & \text { Constraint Tensor } \\ \mathrm{x} & \text { Newtonian effective tensor of viscous } \\ \text { y } & \text { stresses } \\ \text { z } & \text { Relative to the longitudinal component } \\ & \text { Related to the vertical component } \\ & \text { Related to the cross-sectional } \\ & \text { component }\end{array}$

\section{Introduction}

The flows encountered in industrial applications often have a three-dimensional unsteady character. Generally, these flows are turbulent and often coupled with other physical phenomena, for example heat transfer. The dispersion of a passive contaminant emitted in a turbulent flow is an important phenomenon encountered in many heat and mass transfer problems $[1,2]$. Industrial applications include the cooling of electronic component and photovoltaic (PV) modules etc. In many practical situations, these diffusion problems occur in complex turbulent flows disturbed by obstacles and characterized by large structures. More generally, many studies carried out in turbulence over the last forty years have shown the existence of coherent structures in sheared flows, even at relatively high Reynolds numbers. However, it appears that very little of this work has been devoted to the influence of some of these structures in the transport and diffusion problems, except for the case of the dispersion of solid particles [3]. On the other hand, no study has been undertaken on taking into account the cooling of the 
ambient air on the dispersion of the thermal field around two heat sources.

Many studies carried out in turbulence during these last decade, have shown the existence of coherent structures inside the stress flows, even at the high Reynolds numbers. Le Masson [4] has worked on the control of Bénard Von-Karmanin stabilities downstream from a heated obstacle at low Reynolds number, but he does not define all the control parameters of instabilities. Brajon-Socolescu [5] has carried out a numerical study on the Bénard Von-Karman instabilities behind a heated cylinder. Lecordier et al. [6] and Weiss [7] also have worked on the transition control downstream from a 2D obstacle using a source of heat located inside his neared wake. These last two studies were limited because of lack of critical Reynolds number.

In the field of solar photovoltaic (PV), several studies have been developed for the cooling of PV panels. At this effect, several studies have been set up to manufacture hybrid panels combining solar photovoltaic and thermal panels [8]. In some cases, numerical studies have been devoted to the dynamic and thermal behavior of ventilated air slats for double wall applications with or without integration of photovoltaic modules. Among these works, there are analytical studies with strong hypotheses to obtain simplified models; this research included numerical studies based on zone models, CFD simulations and experimental studies on real PV components [9]. However, most of these studies do not depend on the very harsh climate of some regions of Cameroon, as in the extreme north where the ambient temperature is about $413.13 \mathrm{~K}$ during the dry season [10].

In order to more easily highlight the influence of the air treated through an air-ground heat exchanger on the diffusion and mixing process around two heat sources, we undertook to study in advance phenomenon in a more complex situation. In this paper, we will present the study of the thermal field upstream and downstream of a PV solar panel and a linear source of heat cooled by an air-ground heat exchanger by illustrating the influence of the vortex paths on the diffusion of the heat in the pipe.

\section{Materials and Methods}

\subsection{Mathematics Model Used}

2.1.1 Modeling of the Air Temperature at the Outlet of the Air-Ground Heat Exchanger

The elementary heat balance through a length $\mathrm{d} x$ portion of the exchanger tube of Figs. 1 and 2 is written:

$$
\dot{m} . c_{\text {pair }} .\left(T_{x}+d T_{x}-T_{x}\right)=\frac{\cdot d x}{R_{\text {ground }}+R_{\text {gaine }}+R_{\text {conv }}} \cdot\left(T_{\text {ground }}-T_{a(x)}\right)
$$

Avec:

$$
\begin{gathered}
\dot{m} \text { : Air mass flow rate }[\mathrm{kg} / \mathrm{s}] \\
c_{\text {pair }} \text { : Massive heat of air }\left[\frac{\mathrm{J}}{\mathrm{kg} . \mathrm{K}}\right]
\end{gathered}
$$$$
R_{\text {ground }}=\text { Thermal residence between the tube and the ground }\left[\frac{\mathrm{m} . \mathrm{K}}{\mathrm{W}}\right]
$$

$$
R_{\text {ground }}=\frac{1}{\lambda_{\text {ground }} \cdot 2 \pi} \ln \left(\frac{R_{\text {ground }}}{R}\right)
$$

$R_{\text {tube }}$ : Thermal resistance of the buried tube $\left[\frac{\mathrm{m} . \mathrm{K}}{\mathrm{W}}\right]$

$$
R_{\text {tube }}=\frac{1}{\lambda_{\text {tube }} \cdot 2 \pi} \ln \left(\frac{R}{r}\right)
$$


$R_{\text {conv }}$ : Thermal resistance between air and tube $\left[\frac{\mathrm{m} . \mathrm{K}}{\mathrm{W}}\right]$

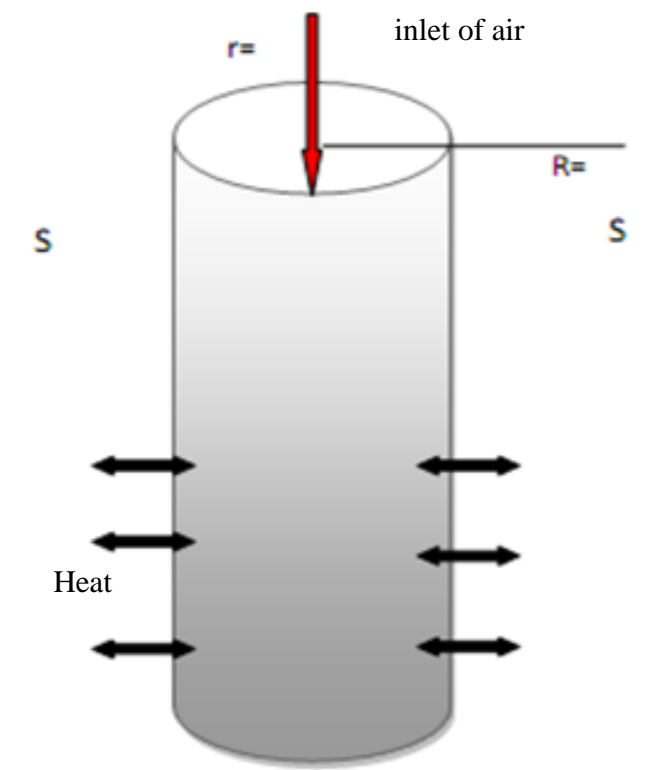

Fig. 1 Heat exchanger between air and ground [11].
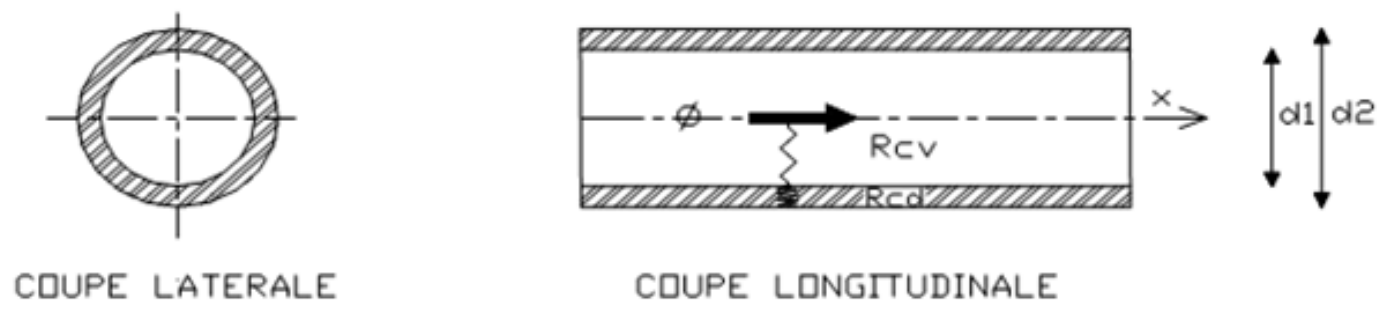

CDUPE LUNGTUDINALE

Fig. 2 Geometry of the pipe forming the buried heat exchanger [12].

$$
R_{\text {conv }}=\frac{1}{h_{\text {conv }} \cdot 2 \pi \cdot r}
$$

$T_{\text {ground }}$ : temperature of ground $[\mathrm{K}]$

where:

$\mathrm{r}$ : Inner radius of the buried tube[m]

$\mathrm{R}$ : Outside radius of the buried tube [m]

$\mathrm{R}_{\mathrm{sol}}$ : Radius of the adiabatic ground layer [m]

$\lambda_{\text {gaine }}$ : thermal conductivity of the buried tube

$\frac{\mathrm{W}}{\mathrm{m} \cdot \mathrm{K}}$

$\lambda_{\text {sol }}$ : Thermal conductivity of the ground $\frac{W}{\mathrm{~m} . \mathrm{K}}$

$\mathrm{h}_{\text {conv }}$ : Coefficient of convection of the air $\frac{\mathrm{W}}{\mathrm{m}^{2} . \mathrm{K}}$

Let $\mathrm{U}$ be the global thermal resistance between air and undisturbed ground defined by:

$$
U=\frac{1}{R_{\text {ground }}+R_{\text {tube }}+R_{\text {conv }}}
$$

Eq. (1) becomes:

$$
\frac{d T_{x}}{T_{\text {ground }}-T_{a(x)}}=\frac{U}{\dot{m} \cdot c_{\text {pair }}} \cdot d x
$$

The integration of Eq. (4) gives such that:

$$
\begin{gathered}
\int \frac{d b}{(a-b)}=\ln (a-b) \\
\ln \left(T_{\text {ground }}-T_{a(x)}\right)=\frac{U}{\dot{m} \cdot c_{\text {pair }}} \cdot x+c
\end{gathered}
$$

To find the value of the constant $c$, it simply returns to the condition at the following boundary condition:

$$
\begin{gathered}
\text { For } \mathrm{x}=0, T_{0}=T_{\text {air-inlet }} \\
\Rightarrow c=\ln \left(T_{\text {ground }}-T_{\text {air-inlet }}\right)
\end{gathered}
$$

By replacing c with its value in Eq. (8) we obtain : 
$\ln \left(\frac{\left(T_{\text {ground }}-T_{a(x)}\right)}{\ln \left(T_{\text {ground }}-T_{\text {air-inlet }}\right)}\right)=\frac{U}{\dot{m} \cdot c_{\text {pair }}} \cdot x$

With:

$$
\ln (a)-\ln (b)=\ln \left(\frac{a}{b}\right)
$$

Therefore, the theoretical air temperature at a certain distance traveled is described by the following mathematical model:

$$
\begin{aligned}
T_{a(x)}=T_{\text {ground }} & +\left(T_{\text {air-inlet }}\right. \\
& \left.-T_{\text {ground }}\right) \cdot e^{\frac{-U}{\dot{m} \cdot c_{\text {pair }}} \cdot x}
\end{aligned}
$$

For a distance $x=1$, it would have as value:

$$
\begin{aligned}
T_{a(x=L)}=T_{\text {ground }} & \\
& +\left(T_{\text {air-inlet }}\right. \\
& \left.-T_{\text {ground }}\right) \cdot e^{\frac{-U}{\dot{m} \cdot c_{\text {pair }}} \cdot l}
\end{aligned}
$$

2.1.2 Modeling of the Temperature Evolution of the Photovoltaic Module

Fig. 3 shows the representation of a PV module that receives sunlight during the day in the absence of external cooling except that of wind.

To have a clear idea about the evolution of the temperature of the PV cells, we made a thermal balance around the PV panel to determine the thermal energy level of the module in the absence of cooling system.

According to the different heat transfer and mass transfer equations, the thermal balance:

Around the transparent glass gave us:

$$
\begin{gathered}
\left.\frac{q}{A}\right)_{s}=h \times\left(T_{c}-T_{a}\right)+\varepsilon_{c}\left(\sigma \times T_{c}{ }^{4}-\sigma \times T_{a}{ }^{4}\right) \\
\Rightarrow \varepsilon_{c} \times \sigma \times T_{c}{ }^{4}+h \times T_{c}-\varepsilon_{c} \times \sigma \times T_{a}{ }^{4} \\
\left.-h \times T_{a}-\frac{q}{A}\right)_{s}=0
\end{gathered}
$$

Solar photovoltaic panels and around aluminium foil:

The external radiosity of the glass gave us:

$$
\begin{gathered}
J_{20}=\sigma T_{\text {module }}{ }^{4}-\left(1-\varepsilon_{c}\right) \times \sigma \times\left(T c^{4}\right. \\
\left.-T_{a}{ }^{4}\right)
\end{gathered}
$$

Around $\mathrm{CD}$ and Air Blade:

$$
\begin{gathered}
\left.\left.\frac{q}{A}\right)_{1}=h_{c o n}\left(T_{1}-T_{c}\right)+\frac{q}{A}\right)_{s} \\
\left.E_{b 1}-F_{12} J_{2 i}=h_{c o n}\left(T_{1}-T_{c}\right)+\frac{q}{A}\right)_{s} \\
\frac{\varepsilon_{c}}{1-\varepsilon_{c}}\left(2 E_{b 2}-J_{2 i}-J_{20}\right) \\
=h_{c o n}\left(T_{1}-T_{c}\right) \\
+h_{v e n t}\left(T_{a}-T_{c}\right) \\
\left.\frac{q}{A}\right)_{\text {rad }}=\varepsilon_{c}\left(E_{b 2}-E_{b 3}\right)=\left(E_{b 2}-J_{20}\right) \frac{\varepsilon_{c}}{1-\varepsilon_{c}} \\
\text { Resolution step: } \quad \\
\frac{\varepsilon_{c}}{1-\varepsilon_{c}}\left[2 E_{b 2}-E_{b 1}-h_{c o n}\left(T_{1}-T_{c}\right)+\frac{q}{A}\right)_{s} \\
\left.-J_{20}\right] \\
=h_{\text {con }}\left(T_{1}-T_{c}\right) \\
+h_{v e n t}\left(T_{a}-T_{c}\right)
\end{gathered}
$$

$\varepsilon_{c}=0.88$ : emissivity of the transparent cover ;

$T_{1}$ : temperature of absorbent plate ;

$\left.\frac{q}{A}\right)_{S}=$ irradiance $\left(\mathrm{W} / \mathrm{m}^{2}\right)$;

$\left.\frac{q}{A}\right)_{1}=$ flow of thermal energy received by

the PV panel and aluminum sheet;

$J_{20}=$ radiosity inside the glass;

$T_{a}=313,15 K$

With $h_{\text {con }}=\frac{k_{e}}{\Delta x}$ where $k_{e}=1.4 k ; k=0.039 ; \Delta x$

$$
\begin{gathered}
=2 \mathrm{~cm} \\
h=h_{\text {vent }}=5.7+3.8 U_{\text {vent }}
\end{gathered}
$$

2.1.3 Energy transport Equations

\subsubsection{Equation of Continuity}

The equation of continuity is given by the equation below:

$$
\begin{aligned}
\frac{D}{D t} \int_{V(t)} \rho d V=0 & \Leftrightarrow \int_{V(t)}\left(\frac{\partial \rho}{\partial t}+\nabla \cdot(\rho \vec{U})\right) d V \\
& =0
\end{aligned}
$$

2.1.3.2 Equations of the Average Quantity of Movement of Navier-Stockes

The conservation equations of the average quantity of movement of Navier-Stockes known by the name 


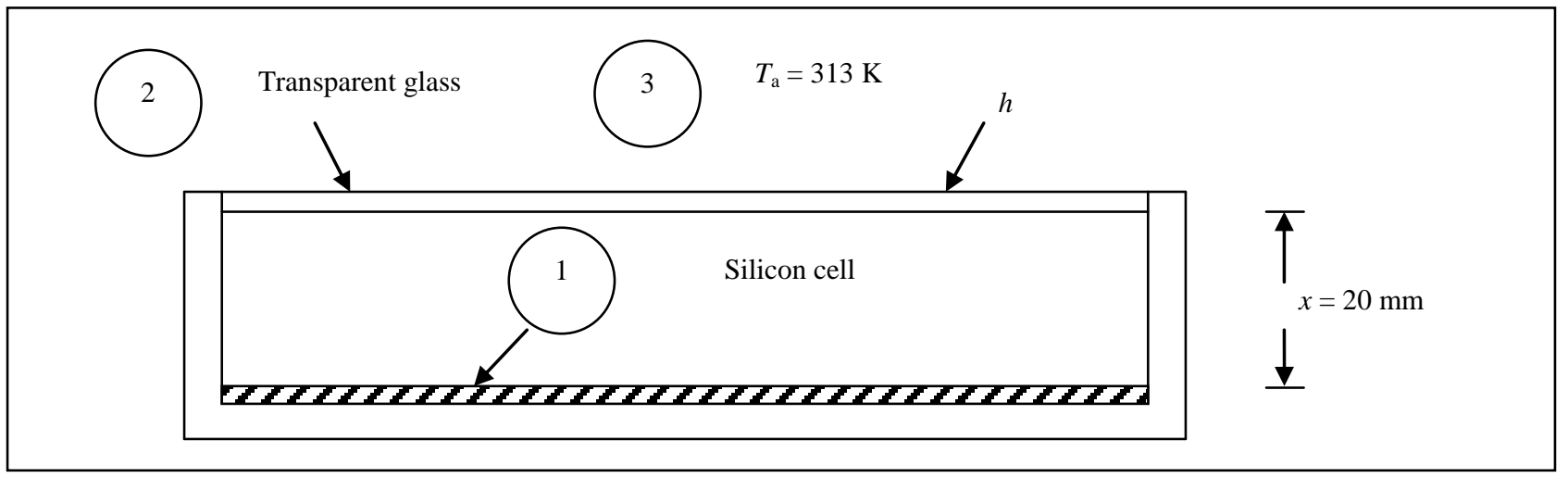

Fig. 3 Photovoltaic module.

RANS are for compressible fluid and Newtonian given by the formula below [13].

$$
\begin{aligned}
& \underbrace{\rho \frac{\partial\left(U_{i}\right)}{\partial t}}_{\text {iation within the volume }}+\underbrace{\rho U_{j} \frac{\partial\left(U_{i}\right)}{\partial x_{j}}}_{\begin{array}{c}
\text { convective } \\
\text { transport }
\end{array}} \\
& =-\frac{\partial P}{\begin{array}{c}
\partial x_{i} \\
\text { forces } \\
\text { due to } \\
\text { pressures }
\end{array}} \\
& +\underbrace{\frac{\partial}{\partial x_{j}}\left[\mu\left(\frac{\partial U_{i}}{\partial x_{j}}+\frac{\partial U_{j}}{\partial x_{i}}\right)\right]}_{\text {viscocity forces }} \\
& -\underbrace{\frac{2}{3} \frac{\partial}{\partial x_{i}}\left(\mu \frac{\partial U_{j}}{\partial x_{j}}\right)}_{\begin{array}{c}
\text { forces } \\
\text { generated by } \\
\text { turbulence }
\end{array}} \\
& +\underbrace{\rho g_{i}}_{\text {volume forces }}
\end{aligned}
$$

$-\rho \overline{u_{\imath}^{\prime} u_{\jmath}^{\prime}}$ are the components of the Reynolds stress tensor. This expression is derived from the Boussinesq concept which allows expressing it in terms of the gradients of the average velocities. This concept is based on the following relation:

$$
-\rho \overline{u_{\imath}^{\prime} u_{j}^{\prime}}=\mu_{t}\left(\frac{\partial u_{i}}{\partial x_{j}}+\frac{\partial u_{j}}{\partial x_{i}}\right)-\frac{2}{3}\left(\rho k+\frac{\partial u_{i}}{\partial x_{j}}\right) \delta_{i j}
$$

The k- $\varepsilon$ turbulence models used during our simulations on the FLUENT software are:

- The standard k- $\varepsilon$ model;

- The k- $\varepsilon$ RNG model;

- The $\mathrm{k}-\varepsilon$ realizable model.
We have used the k- $\varepsilon$ realizable model which is to perform the calculations in the FLUENT software. The model of $k-\varepsilon$ turbulence has been taken into account to correct the deficiencies of the other k- $\varepsilon$ models such as the standard k- $\varepsilon$ model, the k- $\varepsilon$ RNG model, etc. [13], by adopting a new formula for turbulence viscosity involving a $\mathrm{C} \mu$ variable at the origin (proposed by Reynolds) and a new equation for dissipation based on the dynamic equation of vorticity fluctuations.

\subsubsection{Equation for the Realizable k- $\varepsilon$ Model}

The set of transport equations for the realizable k- $\varepsilon$ model are: the turbulent kinetic energy transport equation and the turbulent kinetic energy dissipation rate transport equation.

The equation of the turbulent kinetic energy $(\mathrm{k})$ is given by the following formula:

$$
\begin{aligned}
\frac{\partial}{\partial t}(\rho k)+\frac{\partial}{\partial x_{i}}\left(\rho k u_{j}\right) & \\
= & \frac{\partial}{\partial x_{i}}\left[\left(\mu+\frac{\mu_{t}}{\sigma_{k}}\right) \frac{\partial k}{\partial x_{j}}\right]+G_{k} \\
& +G_{b}-\rho \varepsilon-Y_{M}
\end{aligned}
$$

2.1.3.4 Equation of the Rate of Dissipation of the Turbulent Kinetic Energy $(\varepsilon)$

The equation of the rate of dissipation of the turbulent kinetic energy $(\varepsilon)$ is defined by:

$$
\begin{aligned}
\frac{\partial}{\partial t}(\rho \varepsilon)+\frac{\partial}{\partial x_{j}}\left(\rho \varepsilon u_{j}\right) & \\
& =\frac{\partial}{\partial x_{j}}\left[\left(\mu+\frac{\mu_{t}}{\sigma_{\varepsilon}}\right) \frac{\partial \varepsilon}{\partial x_{j}}\right]+\rho C_{1} S \varepsilon \\
& -\rho C_{2} \frac{\varepsilon^{2}}{k+\sqrt{v \varepsilon}}+C_{1 \varepsilon} \frac{\varepsilon}{k} C_{3 \varepsilon}
\end{aligned}
$$


Table 1 The constants of model.

\begin{tabular}{llll}
\hline$C_{1 \varepsilon}$ & $C_{2}$ & $\sigma_{k}$ & $\sigma_{\varepsilon}$ \\
\hline 1.44 & 1.9 & 1.0 & 1.2 \\
\hline
\end{tabular}

where

$$
\begin{gathered}
C_{1}=\max \left[0.43, \frac{\eta}{\eta+5}\right] \\
\eta=S \frac{k}{\varepsilon}
\end{gathered}
$$

$\mathrm{G}_{\mathrm{k}}$ : the turbulent kinetic energy due to the average speed gradient;

$\mathrm{Gb}$ : generation of turbulent kinetic energy due to buoyancy;

$\mathrm{Y}_{\mathrm{M}}$ : the contribution of the fluctuating dilatation;

$\mathrm{C}_{2}$ and $\mathrm{C}_{1 \varepsilon}$ : the constants and $\sigma_{\mathrm{k}}$ and $\sigma_{\varepsilon}$ the turbulent Prandtl number relative to $\mathrm{k}$ and $\varepsilon$.

The values of constants are represented in Table 1 [14].

\subsection{Boundary Conditions}

2.2.1 Device for Cooling a PV Module and a Linear Source of Heat

Previously, research has shown how electronic components are cooled directly by ambient air providing from the atmosphere. As an illustration, we have the work done by Paranthoën et al. [15] in 2001 whose optic was to illustrate the influence of the turbulent flow of air on the cooling of electronic micro-components often very hot at the moment of their operation.

In addition, in the field of thermal solar photovoltaic, studies like Rosa et al. [16] in 2016 propose an experimental study with the aim of improving the cooling of a solar photovoltaic field.

However, in Cameroon the ambient temperature is much higher than the heat transfer fluid temperature taken into account during the previous studies. As an example in Cameroon, we have the city of Maroua where ambient air regularly reaches $40{ }^{\circ} \mathrm{C}$ during the dry season [10].

The purpose of this article is to study numerically the dispersion of the thermal field in a device composed of an air-ground exchanger charged with cooling the ambient air. At this exchanger, two compartments are connected to the output. In each of these compartments are respectively housed a PV module and a linear source of heat.

The compartment containing the heat source was the subject of the experimental study of Paranthoën et al. [15] in 2001.

The air-to-ground heat exchanger is a pipe assembly (PVC, PHD, Aluminum) with a diameter of $200 \mathrm{~mm}$ and a length of $50 \mathrm{~m}$. As illustrated in Fig. 4, the compartment comprising the PV panel will have a length of 1,700 mm and a width of 1,100 mm (Fig. 4).

Under irradiance of $600 \mathrm{~W} / \mathrm{m}^{2}$ and a temperature of $40{ }^{\circ} \mathrm{C}$, we simulated the evolution of the temperature and the diffusion of heat according to the thermal characteristics of the PV cells and the speed of entry of the wind assuming that we are in the locality of Maroua.

The different simulations that we will do on Fluent, Gambit and Matlab will be done with the data in Table 2.

2.2.2 Experimental Study of Paranthoën et al. [15]

This device (Fig. 5) consists of a parallelepipedal pipe in which the following is housed:

- A cylinder;

- A heat source line.

The main cylinder is at a critical distance of 1.524 $\mathrm{mm}$ from the inlet of the pipe. When the fluid is injected into the pipe, it is this cylinder that generates the turbulence; that is how we talk about wake. After the creation of this coherent structure, it interacts with a linear source of heat placed at $14 \mathrm{~mm}$ from the main cylinder. During our work, it will be a question of characterizing the behavior of the dynamic field and the thermal field downstream of this linear source of heat by taking into account the parameters of control which we will highlight in the continuation of this article.

In this experiment carried out in the air, the main cylinder of diameter $D=2 \mathrm{~mm}$ is placed in the 


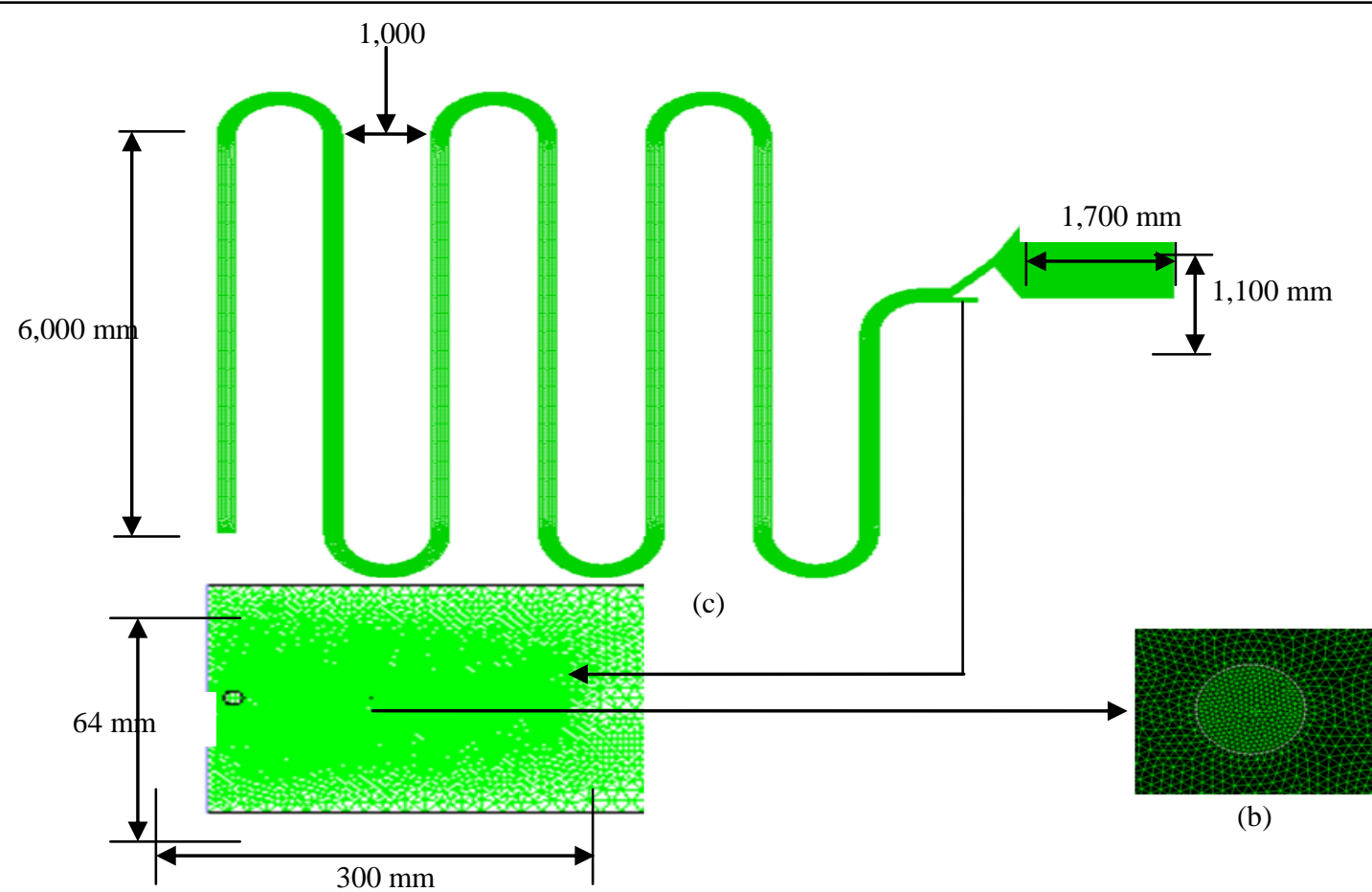

(a)

Fig. 4 Mesh of the computation domain: (a) exact configuration; (b) zoom at the linear source of heat; (c) overview of the system of our study.

Table 2 Values used during the simulation on Fluent, Gambit and Matlab: thermo-physical properties of the materials of the renewable photovoltaic energy recovery system $[13,17,18]$.

\begin{tabular}{ll}
\hline Parameters of renewable energy recovery system & Value \\
\hline PV collector width & $0.997 \mathrm{~m}$ \\
PV collector length & $1.700 \mathrm{~m}$ \\
Peak power of solar panel & $250 \mathrm{Wc}$ \\
Electrical efficiency of the PV panel (STC) & $14.43 \%$ \\
Thermal collector angle & $15^{\circ}$ \\
Thickness of the air channel & $0.02 \mathrm{~m}$ \\
Wind speed & $3.8 \mathrm{~m} / \mathrm{s}$ \\
Glass emissivity & 0.88 \\
Glass thickness & $0.003 \mathrm{~m}$ \\
Thermal conductivity of glass & $1 \mathrm{~W} / \mathrm{m} . \mathrm{K}$ \\
Glass absorption coefficient & 0.066 \\
Glass transmission & 0.95 \\
Thickness of silicon & $0.0003 \mathrm{~m}$ \\
Thermal conductivity of silicon & $0.036 \mathrm{~W} / \mathrm{m} . \mathrm{K}$ \\
Silicon transmission coefficient & 0.87 \\
Emissivity of the PV cell & 0.95 \\
Cell absorption coefficient & 0.85 \\
Thickness of insulation & $0.05 \mathrm{~m}$ \\
Cell filling factor & 0.83 \\
Thermal insulation coefficient & $0.035 \mathrm{~W} / \mathrm{m} . \mathrm{K}$ \\
Cell temperature coefficient & $0.0045^{\circ} \mathrm{C}^{-1}$ \\
\hline
\end{tabular}




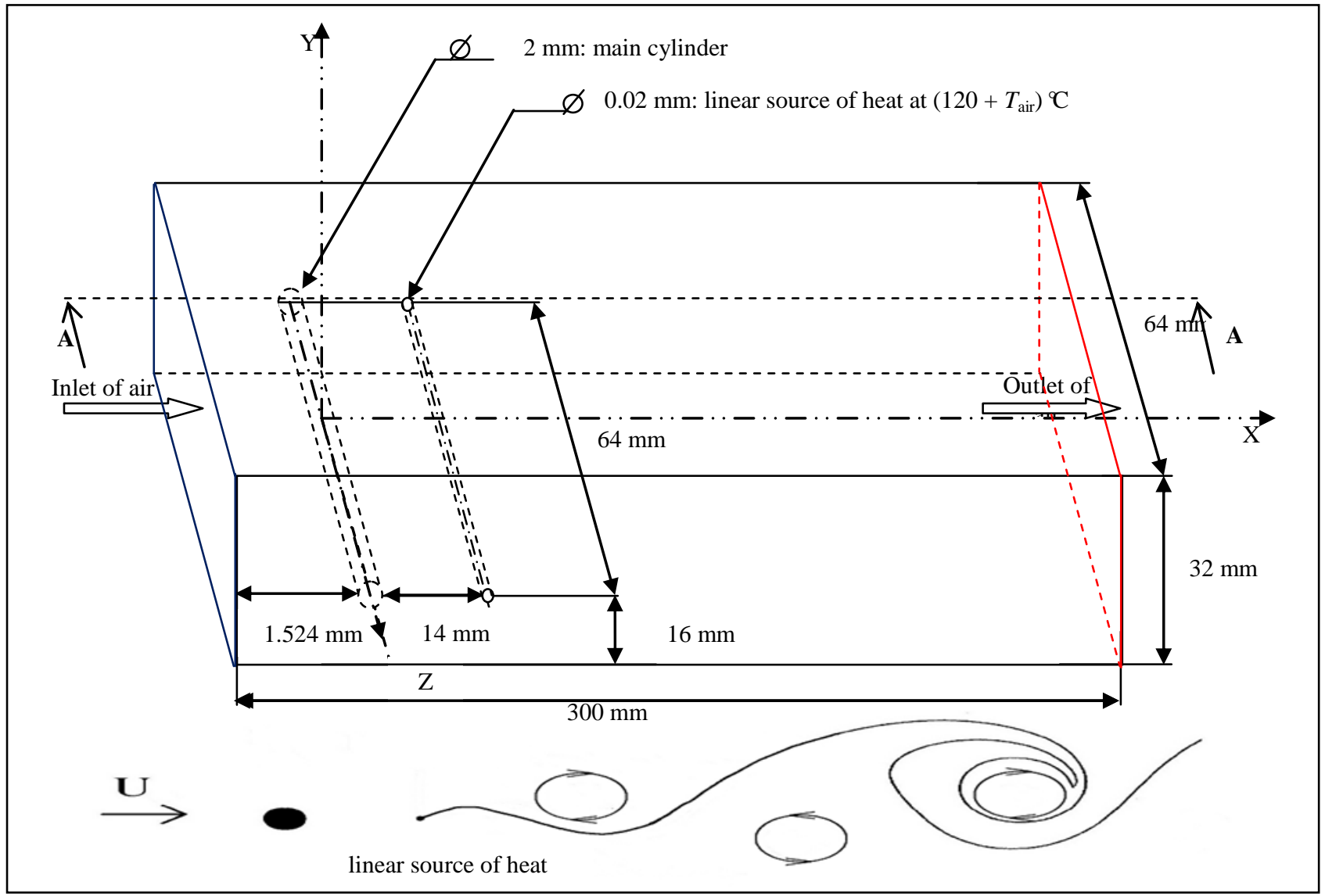

Fig. 5 Geometric configuration of Paranthoen et al. [15].

potential core of a rectangular vertical plane air jet with an initial section of $32 \mathrm{~mm} \times 300 \mathrm{~mm} \times 64 \mathrm{~mm}$ (see Fig. 5). The linear heat source, of diameter $d=$ $0.02 \mathrm{~mm}$, heated by the Joule effect is placed parallel to the main cylinder at an abscissa $\mathrm{x}_{\mathrm{s}}{ }^{+}=7$, on the center line at $\mathrm{y}_{\mathrm{s}}{ }^{+}=0$ and $\mathrm{z}_{\mathrm{s}}{ }^{+}=0$.

In our experiment, the $\mathrm{x}$ axis is in the direction of the main flow, the $y$ axis is horizontal and perpendicular to the cylinder and the linear source, the $\mathrm{z}$ axis is located on the center line of each cylinder. The study zone downstream of the source corresponds to values of $\Delta \mathrm{X}^{+}=\left(\mathrm{x}^{+}-\mathrm{X}_{\mathrm{S}}^{+}\right)$between 1 and 16. The lengths, the velocities $U_{\infty}$ and the temperature differences are respectively normalized by the diameter $D$ of the cylinder, the upstream speed and the temperature difference scale $\Delta \mathrm{T}_{r e f}$ (with $\frac{P}{l}=$ $10 \mathrm{~W} / \mathrm{m})$. The normed quantities include a cross (+) and, the state quantities include an asterisk (*).

\section{Results and Discussion}

\subsection{Study of the Air-Ground Exchanger}

3.1.1 Evolution of the Theoretical Air Temperature according to the Length of the Pipe

To see the effect of the construction material most frequently used in the cooling by buried geothermal heat exchanger, we tried to see the thermal behavior of ambient air inside three types of materials, high pressure PVC, PHD (high density polyethylene) and aluminum. Fig. 6 shows the evolution of the air temperature as a function of length, in the case of a clay soil, in the presence of a $50 \mathrm{~m}$ long exchanger buried at a depth of $3 \mathrm{~m}$, with a tube center distance equal to $1 \mathrm{~m}$, the air flow injected at the inlet of the exchanger is equal to $254.9214 \mathrm{~kg} / \mathrm{h}$ which corresponds to an average speed of $2 \mathrm{~m} / \mathrm{s}$.

The analysis of curves (6) shows that the thermal conductivity of the material is the dominant parameter 


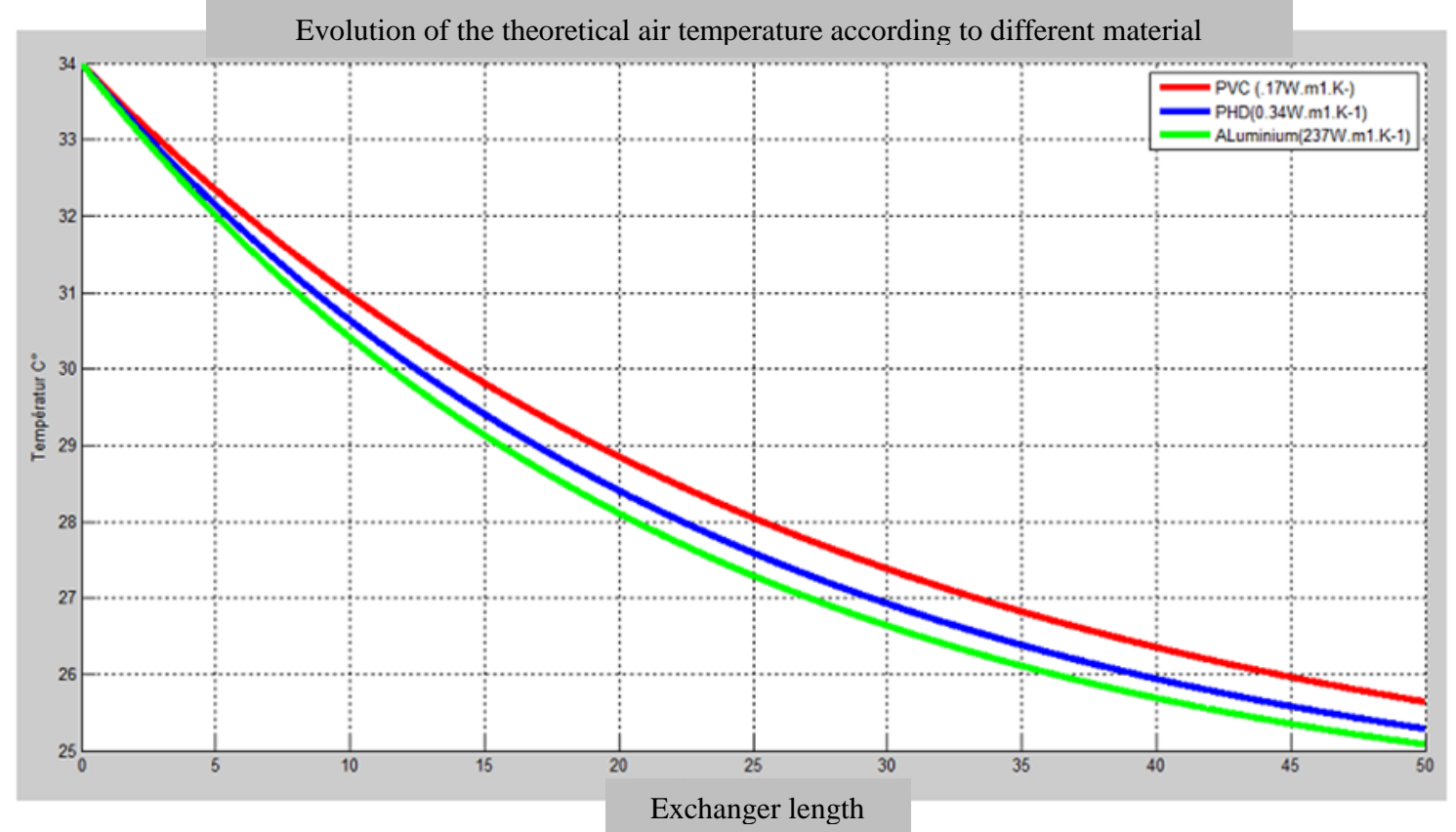

Fig. 6 Evolution of the theoretical air temperature as a function of the length for different materials of construction of the tube of exchanger, buried in a clay soil at a depth of $3 \mathrm{~m}$, of which the injected air flow rate is $V=2 \mathrm{~m} / \mathrm{s}$.

that affects the quality of the heat transfer between the ground and the wall of the buried exchanger tube. In our case, among the three tested materials, an aluminum exchanger $(\lambda=237 \mathrm{~W} / \mathrm{m} \cdot \mathrm{K})$ represents good thermal performance compared to a PVC exchanger $(\lambda=0.17 \mathrm{~W} / \mathrm{m} \cdot \mathrm{K})$.

However, in practical applications, manufacturers prefer high-pressure PVC because of these numerous advantages, in particular its low cost of production and its resistance to corrosion in the presence of wet soils. On the other hand, despite its low thermal conductivity, the temperature difference as a function of the length of the exchanger to reach the soil temperature is not very important compared to metallic materials which are good conductors, but which have a disability with respect to corrosion resistance.

3.1.2 Average Temperature in the Air-Ground Heat Exchanger

Figs. 7 and 8 show the evaluation of the average temperature of the air circulating inside our air-to-ground heat exchanger. The ambient air enters the position $(0,1,0)$ with an ambient temperature of
413.963 K. After 6 meters of travel in the PVC pipe, the air temperature decreases until reaching the temperature of $311.588 \mathrm{~K}$. From the position $(0,1,6)$, the air temperature decreases from $311.588 \mathrm{~K}$ to $307.214 \mathrm{~K}$ at $(1,4,-0.6)$. Between this previous position and the point $(3,6,4)$, the air temperature goes from $307.214 \mathrm{~K}$ to $302.84 \mathrm{~K}$. This process continues progressively between the point $(3,6,4)$ and stabilizes at the temperature equal to $296.278 \mathrm{~K}$ at the coordinate point $(6,1,1.4)$.

As a result of this simulation we can say that the ambient air that enters the ambient temperature of $413.963 \mathrm{~K}$ is cooled then reaches a stable temperature of $296.278 \mathrm{~K}$ after having traveled a length of $42.3956 \mathrm{~m}$.

By increasing the air inlet speed to $3.8 \mathrm{~m} / \mathrm{s}$, we find that air cooling is accelerating considerably. After $38.3965 \mathrm{~m}$ the air reaches a temperature of $301.754 \mathrm{~K}$.

Indeed, after having traveled a length of $5 \mathrm{~m}$, the ambient air passes from the temperature of $313.15 \mathrm{~K}$ to the value of $310.188 \mathrm{~K}$. Between the coordinate point $(0,1,5)$ and the point $(2,5,1)$ the air temperature decreases to the value of $307.377 \mathrm{~K}$. The 


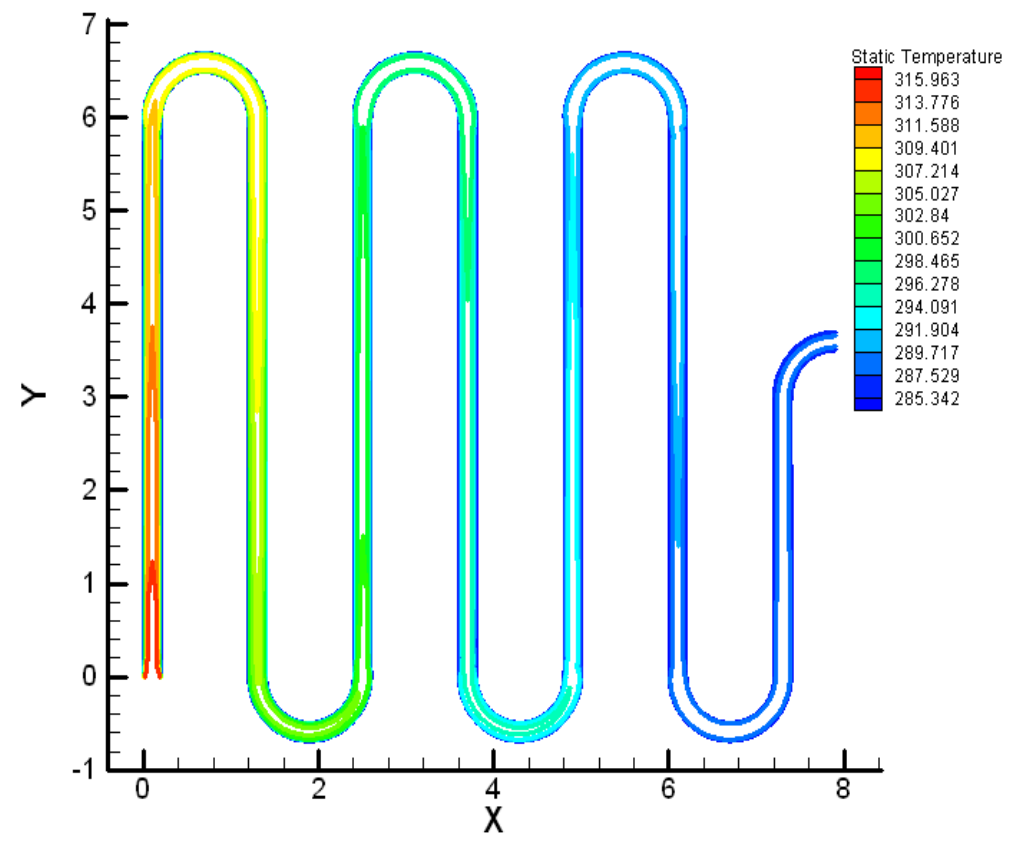

Fig. 7 Mean temperature in the air-ground heat exchanger for an input speed of $V=2 \mathrm{~m} / \mathrm{s}$.

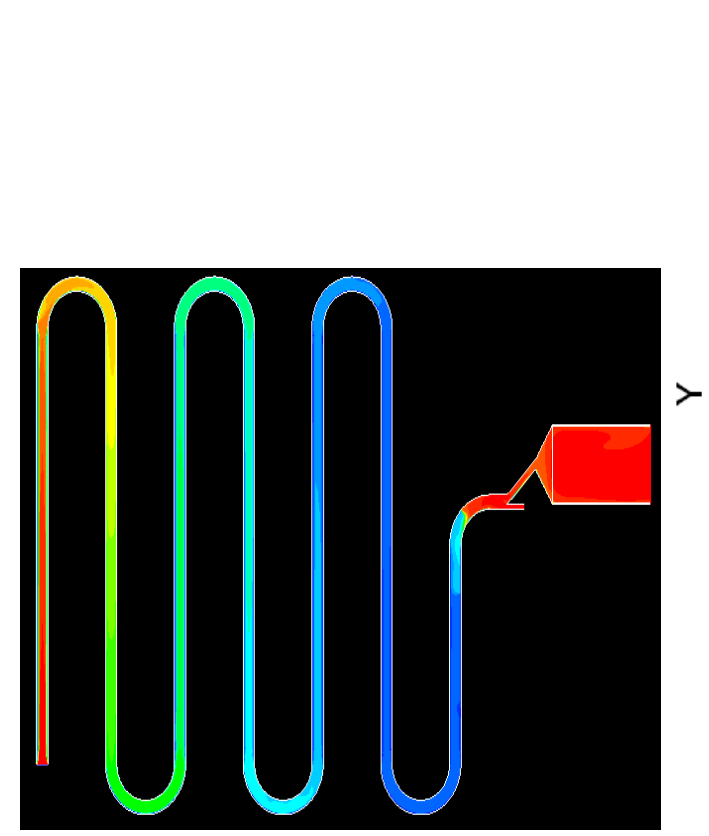

(a)

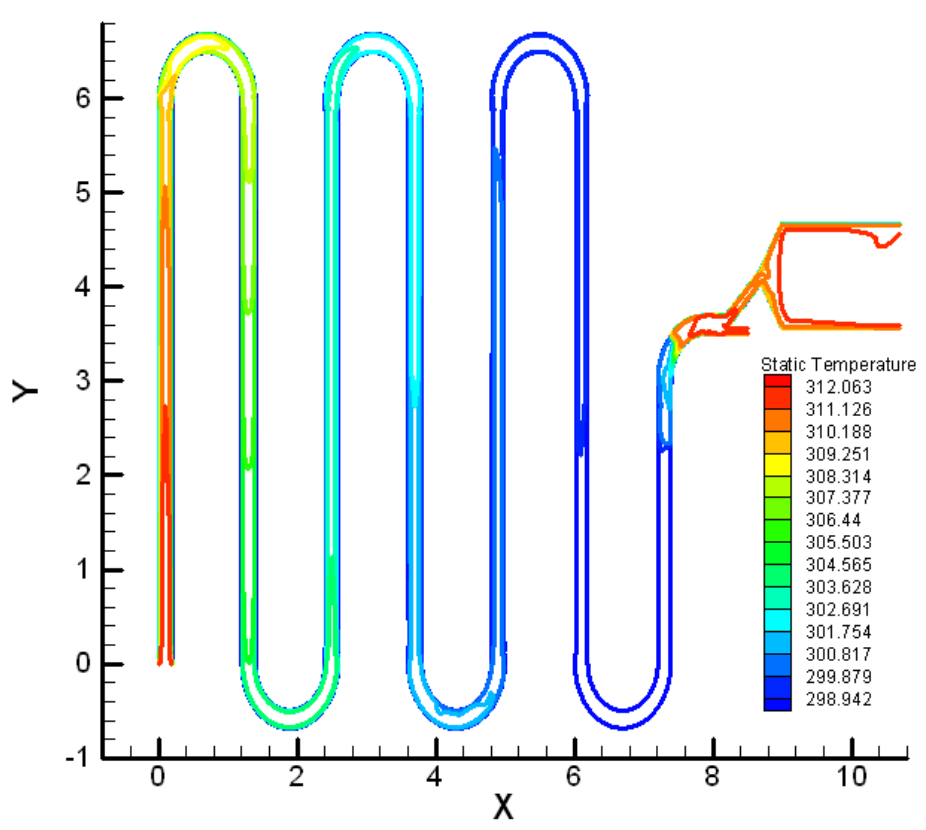

(b)

Fig. 8 Average temperature in the air-ground heat exchanger connected to the two heat sources for an input speed $V=3.8$ $\mathrm{m} / \mathrm{s}$ : (a) figure obtained on Fluent; (b) figure obtained on Tecplot.

same process continues to the coordinate point $(4,5,5)$ where the air reaches the temperature of $301.754 \mathrm{~K}$.

\subsection{Comparative Study of the Thermal Field in the PV/T Collector}

In this section, it is a question of making a comparative study between a PV module cooled directly with the ambient air and a PV module cooled by the ambient air previously cooled by an air-ground heat exchanger.

For irradiance of $600 \mathrm{~W} / \mathrm{m}^{2}$, we made simulations on the Fluent software. The two studies below 
illustrate the evolution of the thermal field around a module directly cooled by air (on the left) and the irradiance reaches $600 \mathrm{~W} / \mathrm{m}^{2}$, PV sensors warm up to $342.3612 \mathrm{~K}$ under ambient air maintained at $313.15 \mathrm{~K}$.

For the air velocity blown at $2 \mathrm{~m} / \mathrm{s}$, this results in a clear yellow diffusion above and below the panel. This diffusion results in the cooling of the internal enclosure of the PV module. The panel is cooled to a temperature of $348.483 \mathrm{~K}$.

Subsequently, when using ambient air cooled by an air-ground heat exchanger, the heat diffusion is faster and the thermal limit layer at the edge of the absorbers is maintained at a temperature of $317.861 \mathrm{~K}$.

\subsection{Study of the Device of Paranthoën et al. [15] in 2001}

\subsubsection{Instantaneous Heat Flux around ISO-Linear} Heat Source

In this part, we present step by step the heat dispersion in the pipe. The different paradigms essential for the understanding of the notion of dispersion are the scalars of temperatures and speeds. Figs. 10-12 show the iso-values of the instantaneous heat flux for Reynolds number values of 63, 700 and 900 .

It can be noted that, in the central part of the thermal plume, the largest flows are always directed

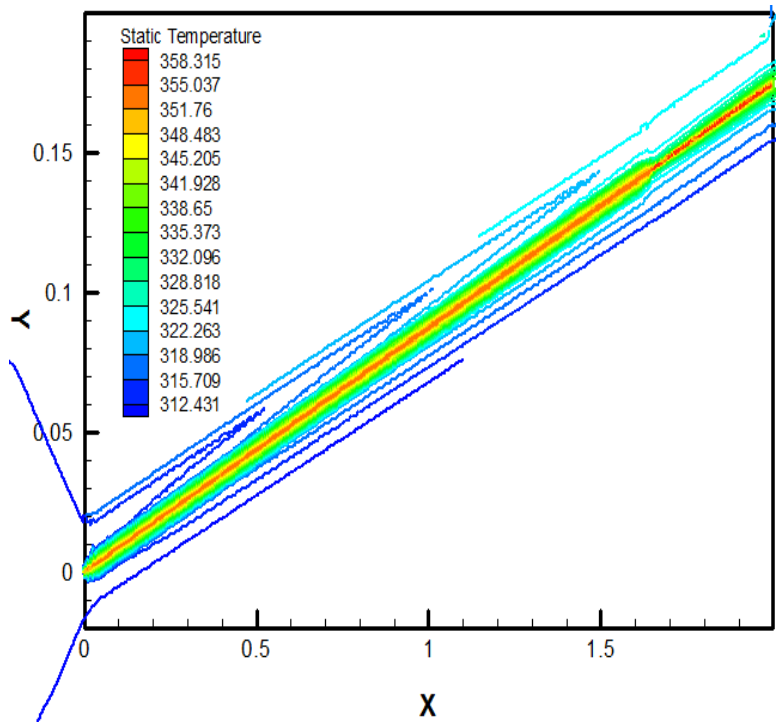

outwards and effectively raise the average temperature gradient.

Fig. 10 illustrated above represents the evolution of the instantaneous heat flux, iso-velocity and isothermal in the dimensioned plane $\left(\mathrm{X}^{+}, \mathrm{Y}^{+}\right)$. Upstream of the heat source, we observe the progression of the wake (yellow color) produced by the main cylinder. This wake progresses and completely envelops the linear source of heat. Subsequently, the phenomenon of heat dispersion in the pipe occurs. From the thermal point of view, the instantaneous heat flux contour results from the mixed convective heat exchange between this wake and the heat source. In addition, we find that downstream of the linear source of heat, we have a very good dispersion of the instantaneous heat flux. This dispersion follows an increasing evolution up to the point $\mathrm{X}^{+}=40$, before converging at the point $\mathrm{X}^{+}$ $=104$. On the zoomed part, we notice that, the flow disperses more at the level of the central line of the path of the wake. The thickness of the thermal field resulting from this dispersion is approximately equivalent to the thickness of the vortex formed at the leading edges of the main cylinder (Fig. 9). Thanks to these results, we can predict a priori on the one hand that the lift of the flow is evaluated at $\mathrm{X}^{+}=104$ and secondly that the dispersion of the heat flow is contained in the wake produced by the main cylinder.

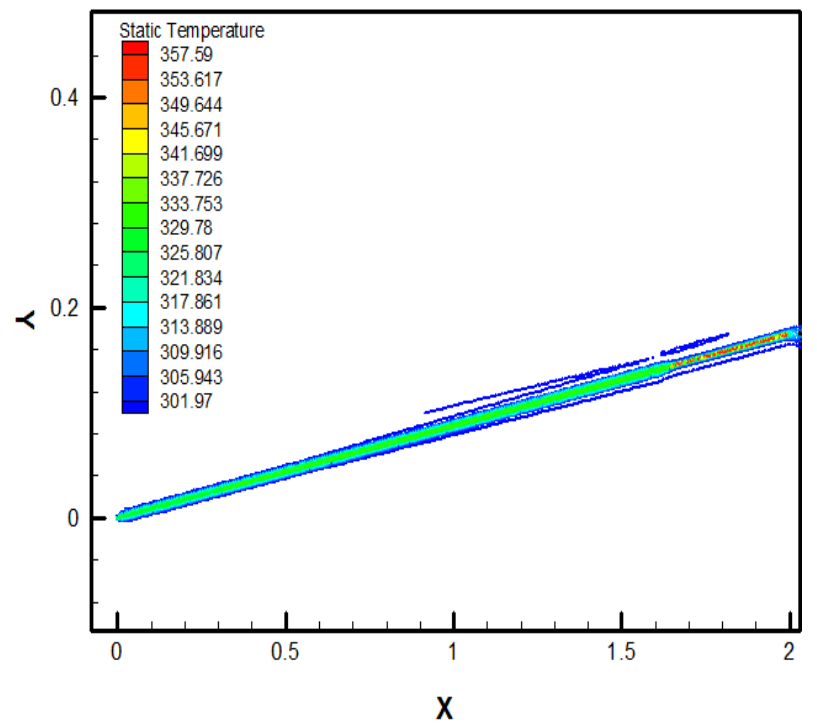

Fig. 9 Average temperature in the plane $(X, Y)$ : left for $G=600 \mathrm{~W} / \mathrm{m}^{2}, T=313.15 \mathrm{~K}$. 


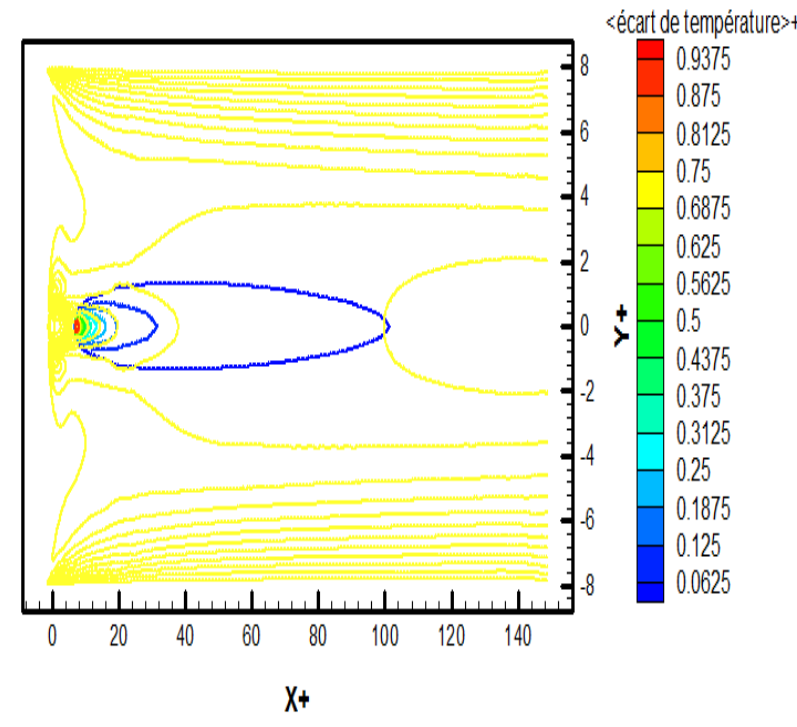

(a)

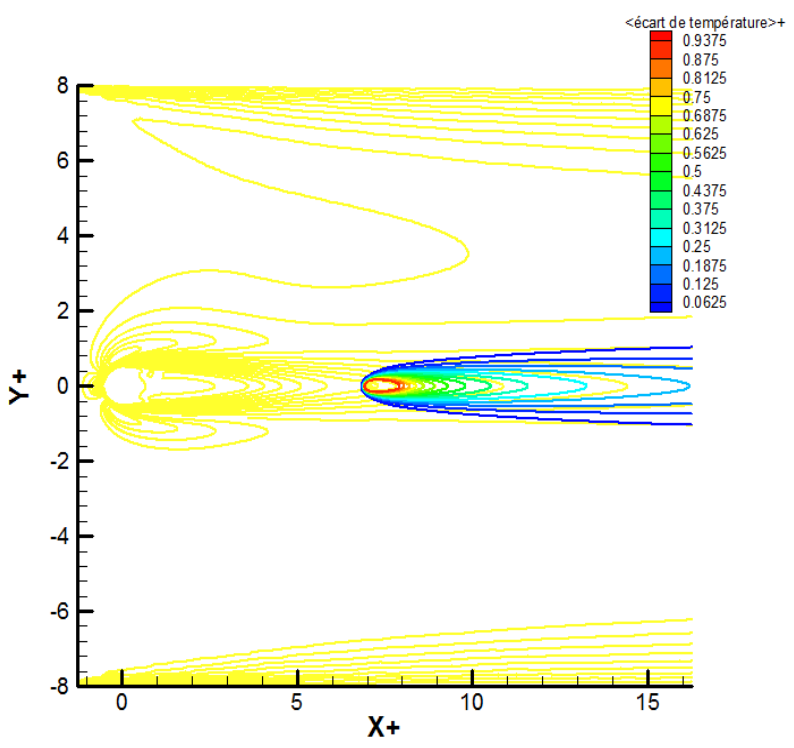

(b)

Fig. 10 Iso-values of the instantaneous heat flux for $\operatorname{Re}=63$ (iso-velocity $=$ yellow, iso-temperature $=$ multi-color, heat flux $=$ blue): (a) normal contour; (b) normal zoomed outline.

Fig. 11 shown illustrates the evolution of iso-heat flux. On this contour, the wake is released faster than previously while oscillating around the center line of the aisle of the flow. This change in the contour of the iso-speeds has repercussions on the dispersion of the instantaneous heat flux. Here, in fact, the flow becomes oscillating and, one can notice that at the point of abscissa $\mathrm{X}^{+}=10$, we have the beginning of appearance of the alleys of Bénard-Von-Karman downstream of the linear source of heat. These results are best illustrated on the zoomed outline. Thus, unlike the results of Paranthoën et al. [13, 15] in 2001 (see Fig. 12), where, from $\mathrm{Re}=63$ they obtained these paths, we on the other hand, observed the formation of these for $\operatorname{Re}=700$ and $\operatorname{Re}=900$ (see Figs. 11 and 12). This coherent structure is very essential for the prediction and the control of the cooling in electronics, in the drying processes since they can be generated by an electronic component like the capacitor.

Fig. 12 shown illustrates the evolution of iso-speed, isothermal and heat flow. As in the previous case, we have an increase in vortices that affect the dispersion of the heat flow downstream of the linear source of heat. However, the formation of Benard-Von-Karman alleys is narrower than when $\operatorname{Re}=700$ : we can explain this by the fact that at one this speed $(\operatorname{Re}=$ 900) the vortex of $2 \mathrm{D}$ nature is transformed into $3 \mathrm{D}$ nature [19]. Nevertheless, these paths oscillate at a shorter oscillation period but the starting point of the oscillation is the same $\mathrm{X}^{+}=10$. These results are better illustrated on the contour (Fig. 12c) where, as previously, the flux is maximal at the point of ordinate $\mathrm{Y}^{+}=-0.5$ and $\mathrm{Y}^{+}=0.5$. We can note that, in the central part of the thermal plume, the largest heat fluxes are always directed outward and, effectively, go up the average temperature gradient.

3.3.2 Evolution of the Adimensioned Vertical Velocity Downstream of the Linear Source of Heat $\mathrm{Y}^{+}$ $=\mathrm{f}\left(\mathrm{U}^{+}\right)$

In this part, the influence of the obstacles is highlighted to explain the progression of the vertical speed in the air duct. The control parameter is the Reynolds number. The objective is to highlight the effect of both obstacles on the stability and instability of the dynamic field.

Figs. 13-15 represent the comparison of the adimensioned speed profiles $\mathrm{Y}^{+}=\mathrm{f}\left(\mathrm{U}^{+}\right)$to $\mathrm{X}^{+}$equal to $8,9,11,15$ and 23 as a function of the different Reynolds numbers Re respectively corresponding to 63, 126, 252, 504, 700 and 900. 


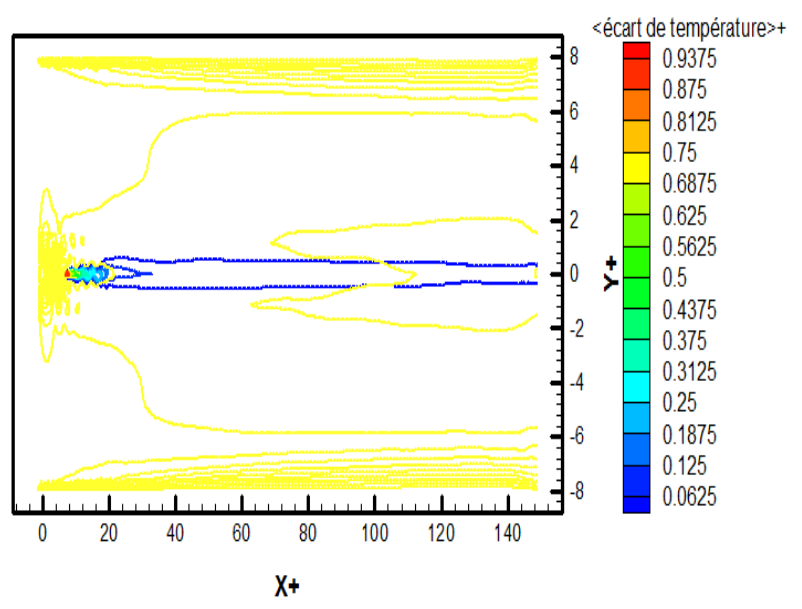

(a)

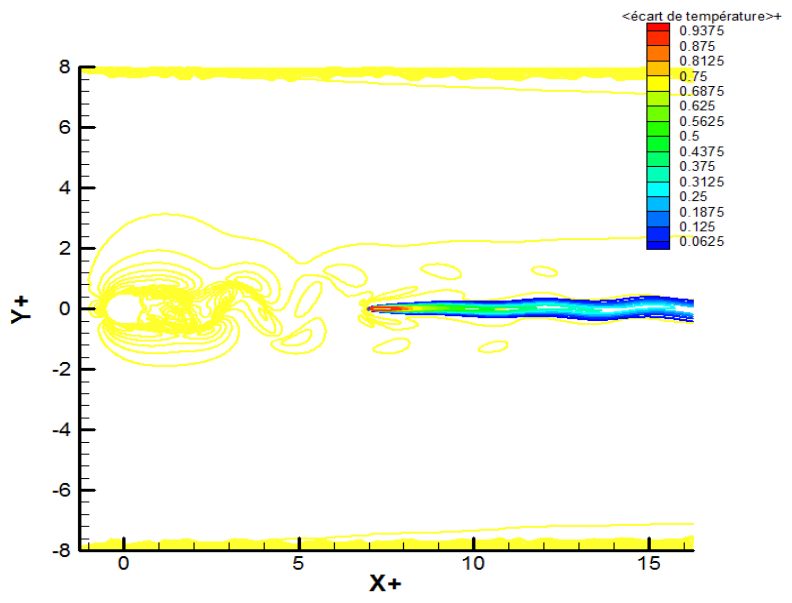

(b)

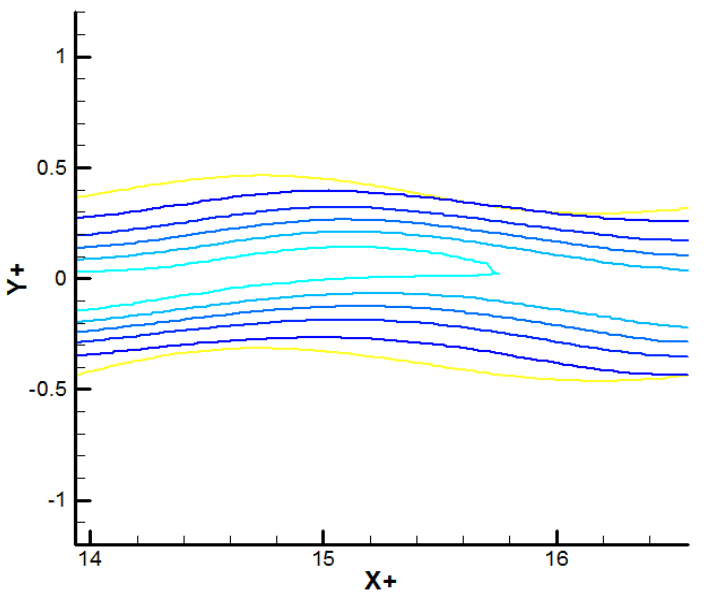

(c)

Fig. 11 Iso-values of the instantaneous heat flux for $\mathrm{Re}=\mathbf{7 0 0}$ (iso-velocity = yellow, iso-temperature = multi-color, heat flux = blue): (a) normal contour; (b) normal zoomed outline at $X^{+}=15$.

The first two profiles (Figs. 13a and 13b) illustrate the progression of the adimensioned vertical air velocity profiles on either side of the two obstacles in our study (cylinder and linear heat source). We note that the speed profile experiences the effect of both obstacles at the center line of the driveway. The deformation is more noticeable when it is at the $\mathrm{X}^{+}=$ 8 position than at the $X^{+}=9$ position. In addition, for $\operatorname{Re}=63$, the evolution of the velocity profile is not deformed at this point except at the level of the walls because of the presence of the boundary layers. On the other hand, when it rises to the maximum value $\mathrm{Re}=$ 900 , the flow of air is considerably deformed. Indeed, the increase in the number of Reynolds creates other buoyancy forces that combined with the effect of obstacles which created a hollow at the center of the aisles. These troughs decrease as Re decreases and $\mathrm{X}^{+}$ increases. For these two positions we can thus say that, the two obstacles influence the evolution of the velocity profile. In this case, they are responsible for the instability of the coolant.

The two profiles (Fig. 14) represent the evolution of the vertical speed adimensionned for several values of Re. Downstream of the source, the hollow generated by the effect of the two obstacles decreases as we move away from the position of the linear source of heat. This change is proportional on the one hand, to the variation of the Reynolds number except the case of the profile obtained for $\operatorname{Re}=63$ where, the speed keeps an identical profile and, with the increase of the 


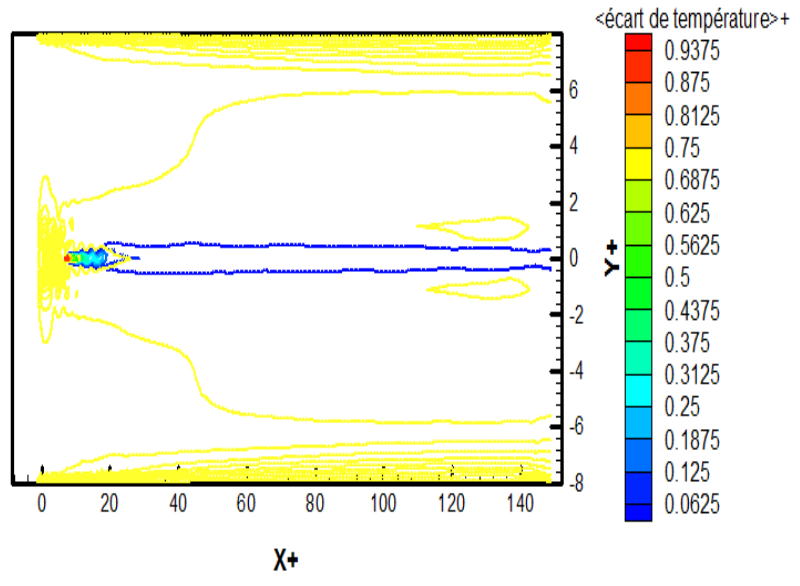

(a)

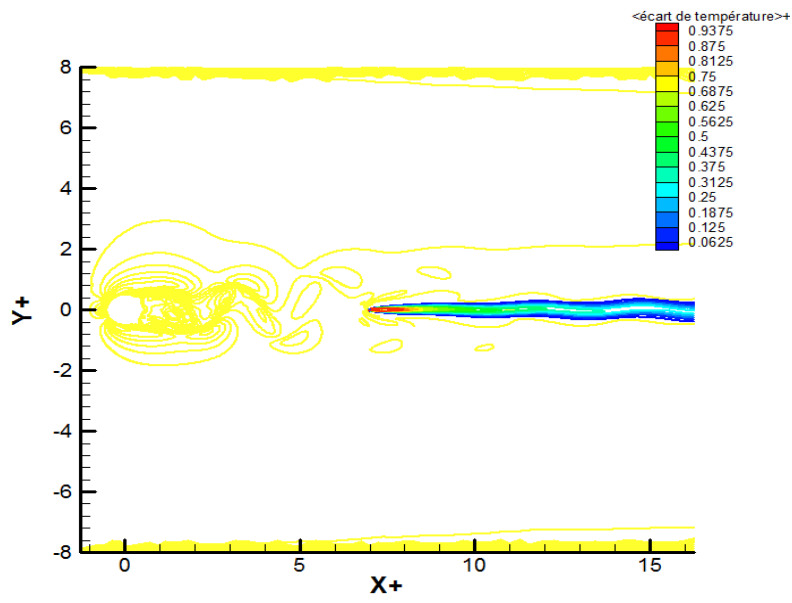

(b)

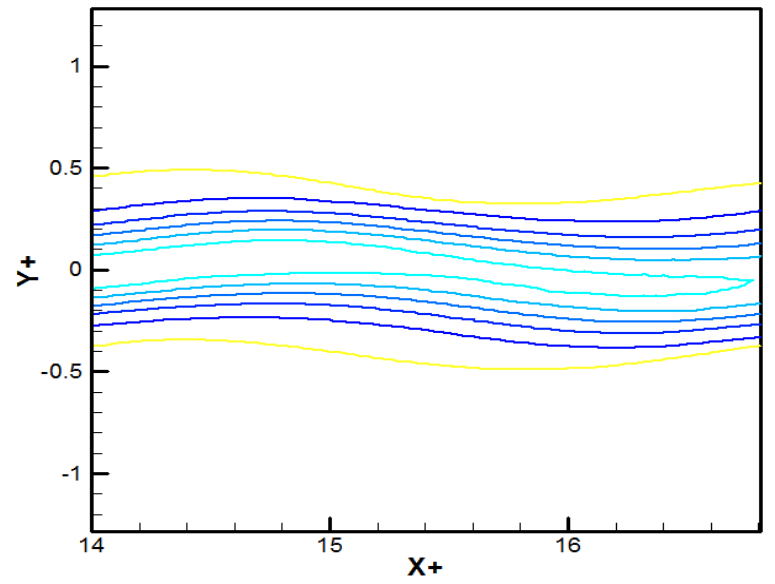

(c)

Fig. 12 Iso-values of the instantaneous heat flux for $\mathrm{Re}=900$ (iso-velocity = yellow, iso-temperature $=$ multi-color, heat flux = blue): (a) normal contour; (b) normal zoomed outline at $\mathrm{X}^{+}=15$.

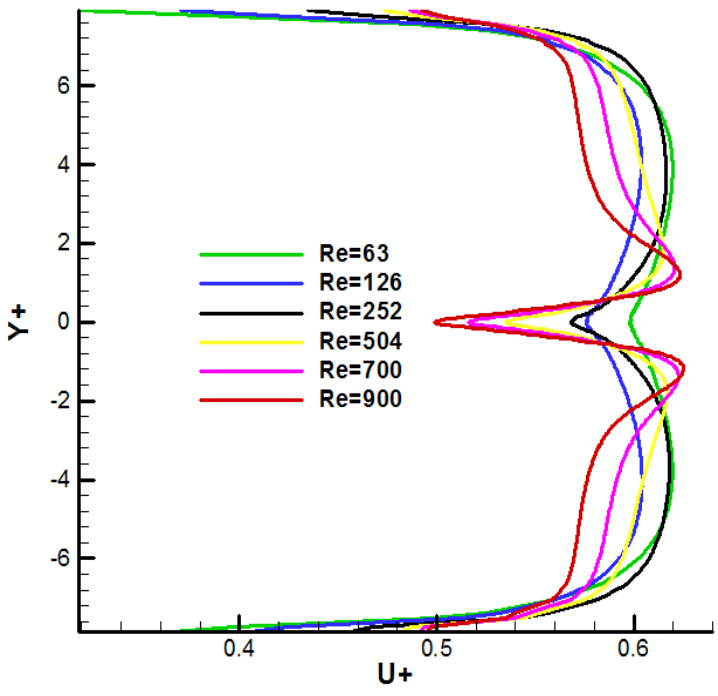

(a)

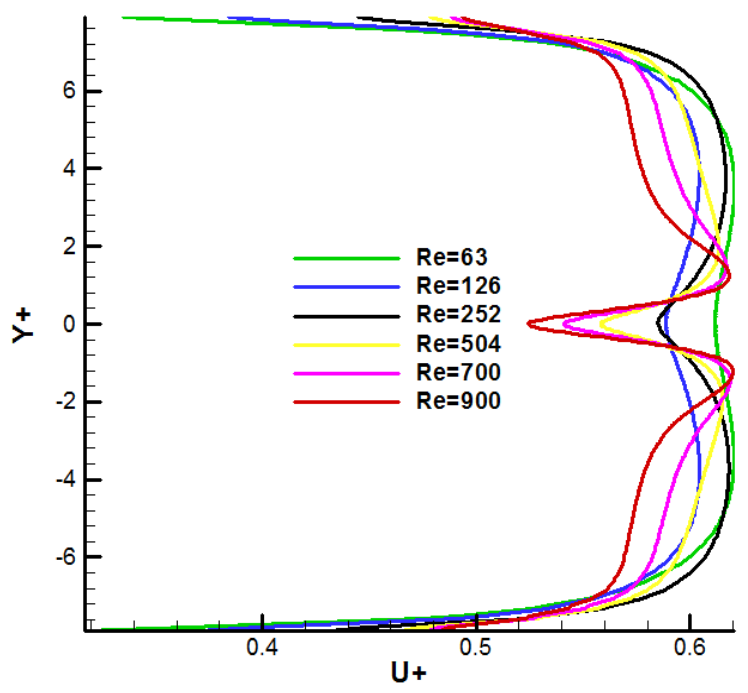

(b)

Fig. 13 Evolution of the adimensionned vertical velocity downstream of the linear source of heat: $(a) \mathbf{Y}^{+}=\mathbf{f}\left(U^{+}\right)$for $X^{+}=8$, (b) $\mathrm{Y}^{+}=\mathbf{f}\left(\mathrm{U}^{+}\right)$for $\mathrm{X}^{+}=9$. 


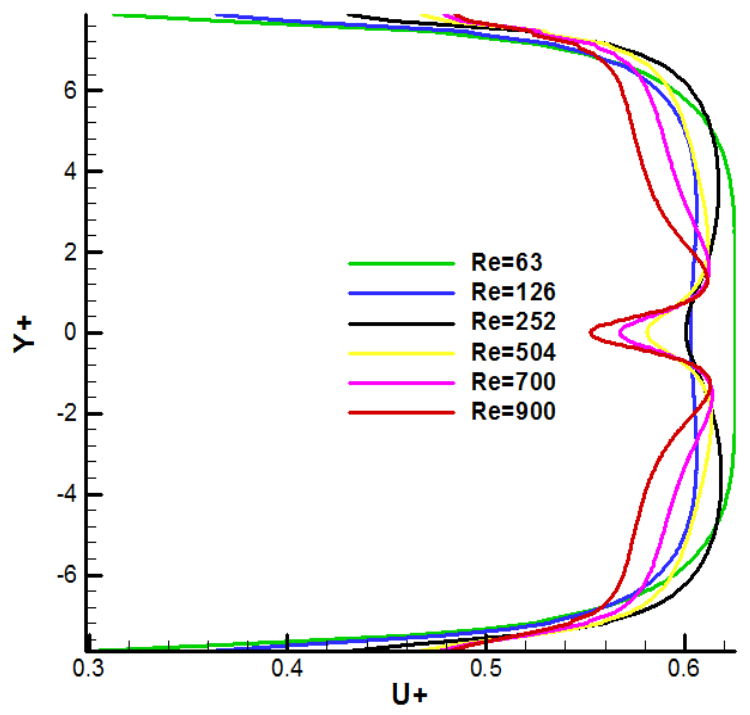

(a)

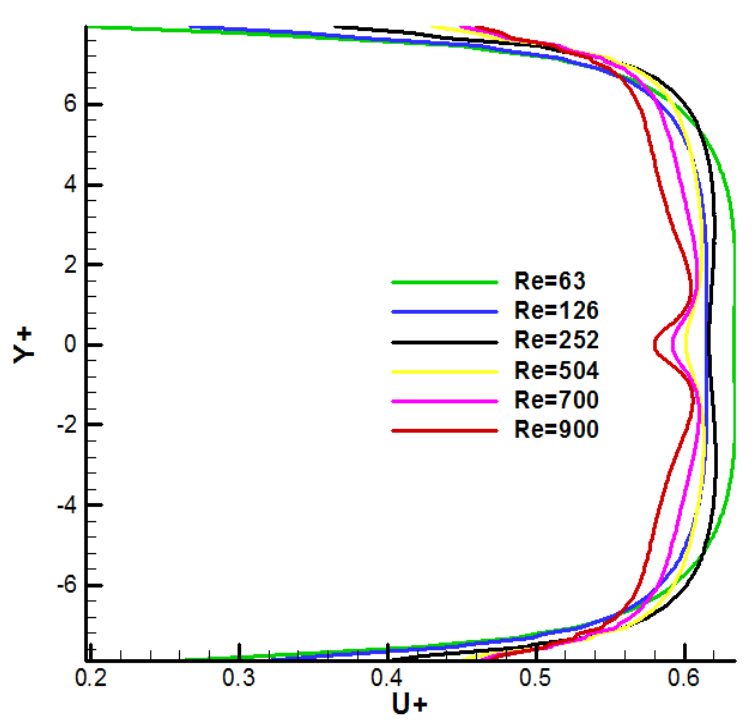

(b)

Fig. 14 Evolution of the adimensionned (vertical) velocity downstream of the linear source of heat: $(a) Y^{+}=f\left(U^{+}\right)$for $X^{+}=$ 11; (b) $\mathrm{Y}^{+}=\mathrm{f}\left(\mathrm{U}^{+}\right)$for $\mathrm{X}^{+}=15$.

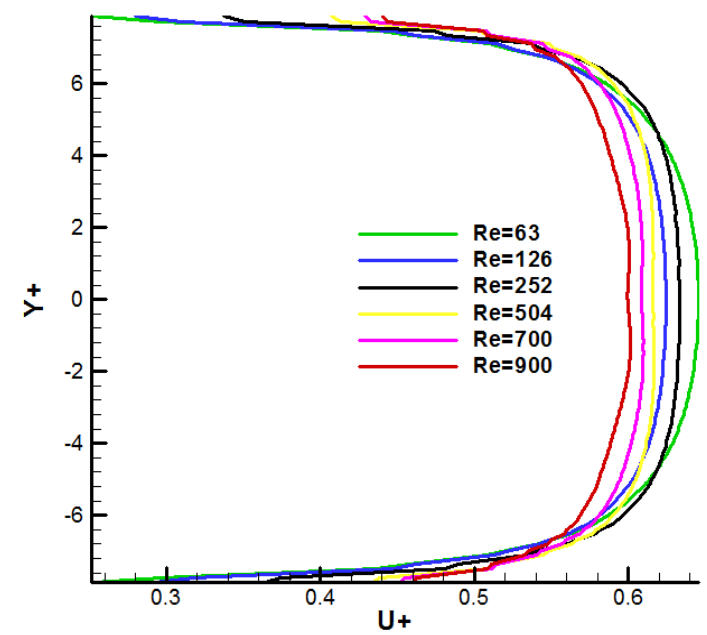

Fig. 15 Evolution of the adimensionned vertical velocity downstream of the linear heat source $\mathrm{Y}^{+}=\mathbf{f}\left(\mathrm{U}^{+}\right)$for $\mathrm{X}^{+}=$ 23.

value of $\mathrm{X}^{+}$. Indeed, we note that, the increase of the number of $\mathrm{Re}$ increases the depth of the hollows which, marks the presence of the obstacles and, these hollows decrease as and when the fluid moves away from the linear source of heat (see Fig. 14 for $\mathrm{X}^{+}=11$ and $X^{+}=15$ ). The presence of the linear source of heat is therefore not the source of the instability of the fluid because, the effect of the instability generated at the point $\mathrm{X}^{+}=11$ is attenuated at the point $\mathrm{X}^{+}=15$. The true instability as we have already stated is caused by the presence of the main cylinder.
For these different velocity profiles (Fig. 15) obtained for several Reynolds numbers, we find that at the point $\mathrm{X}^{+}=23$, the velocities keep uniform which are distinguished by the variation of the Reynolds number. In fact, the bigger the Re, the higher the lift of the vertical speed profile is reduced. That is why; for $\operatorname{Re}=900$, we have the lowest lift, where $\operatorname{Re}=63$, for which we have better lift. From the above, we can say that the choice of the position of $\mathrm{X}^{+}$makes it possible to evaluate the influence of the obstacles on the progression of the velocity profile because, at the position $\mathrm{X}^{+}=23$, the two obstacles have more than significant effect. In addition, the increase of other forces (buoyancy) has the effect of reducing air lift.

Thus, as the force of inertia increases, the forces of Magnus stated by Paranthoen et al. [13, 19] increase and result in forces that are contrary to the fluid flow.

\section{Comparison of Numerical and Experimental Results}

4.1 Comparison of the Transversal Velocity-Temperature Correlation Profiles $\left\langle v^{\prime} T^{\prime}\right\rangle{ }^{+}=$ $f\left(Y^{+}\right)$Numerical and Experimental at $X^{+}=8, X^{+}=9$, $X^{+}=11, X^{+}=15, X^{+}=23$ and $\operatorname{Re}=63$

The two graphs (Figs. 16a and 16b) below are 
graphical representations of the velocity-temperature correlation profile obtained by numerical simulation and, by experimental measurement. On these, we notice that the profiles are similar and that the numerical and experimental curves are superimposed in the same way. However, their larger and smaller values are different. These values are almost identical for the profiles obtained at the point $\Delta \mathrm{X}^{+}=1$. Based on these results, we see a clear similarity between our numerical results and the experimental results of

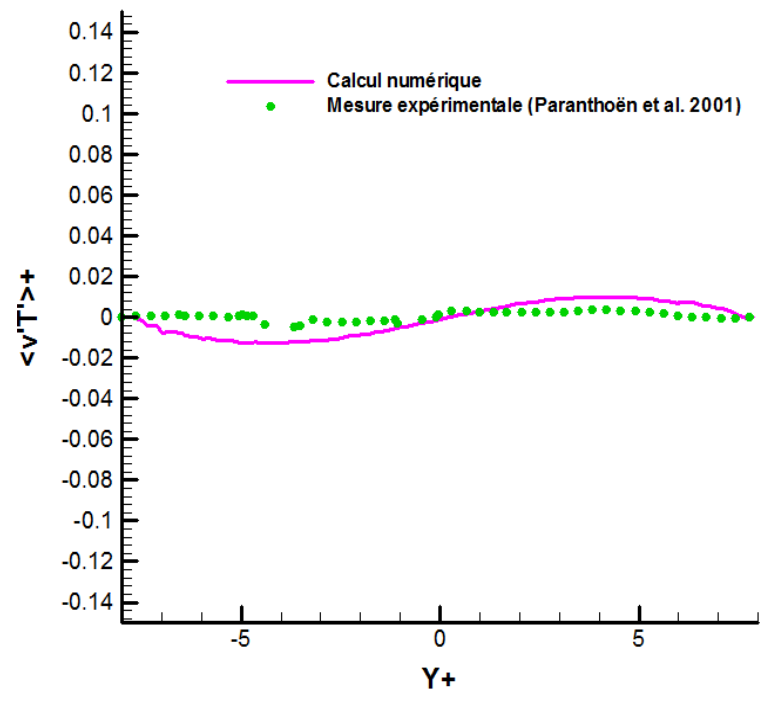

(a)
Paranthoën et al. $[13,15]$, which justifies the validity of the other results presented above.

Fig. 16 above represents the profiles of $\langle\mathrm{v} \text { 'T ' }\rangle^{+}$ obtained at distances of 1, 2, 4, 8 and 16 diameters from the source when $\mathrm{ys}^{+}=0$. It can be noted that in the central zone of the plume thermal, the correlation $\left\langle\mathrm{v}^{\prime T}{ }^{\prime}\right\rangle{ }^{+}$always has the same sign as the gradient $<\partial \Delta \mathrm{T} / \partial \mathrm{y}>^{+}$(Fig. 17). This result indicates that the linear model of gradient transport is unsuitable in this area. This result

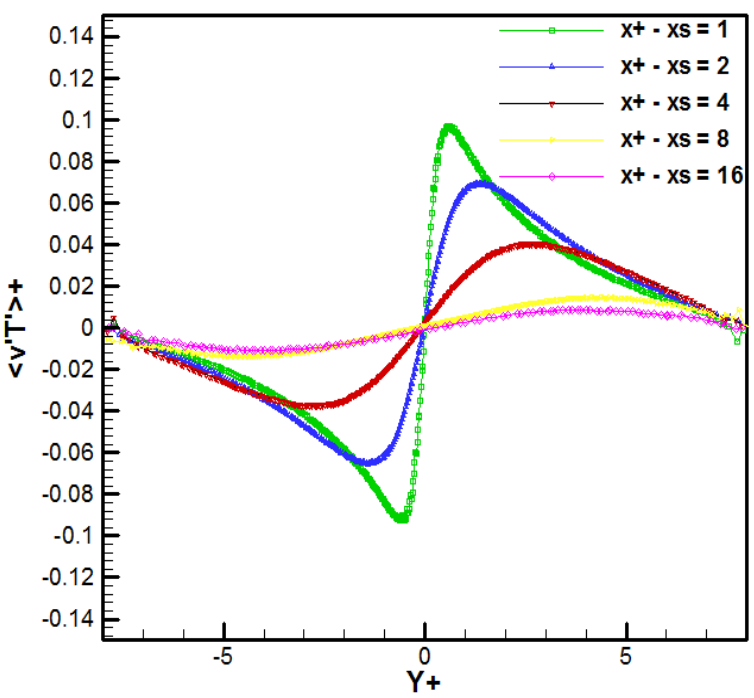

(b)

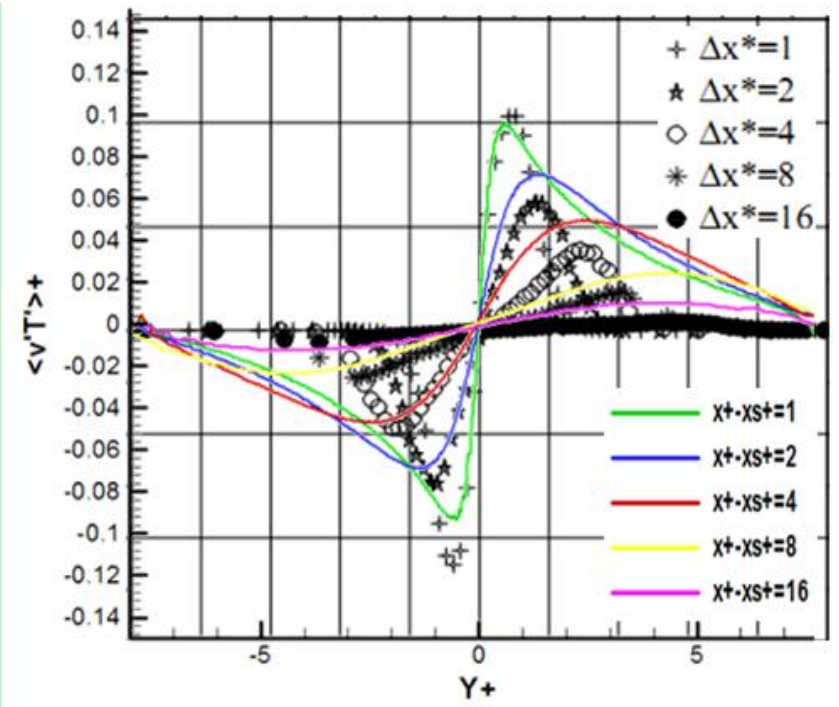

(c)

Fig. 16 Comparison of the numerical and experimental cross-temperature correlation profiles $\left\langle\mathrm{v}^{\prime} \mathrm{T}^{\prime}\right\rangle^{+}=\mathbf{f}\left(\mathrm{Y}^{+}\right)$numerical and experimental for $\operatorname{Re}=63$ : (a) to $\mathrm{X}^{+}=23$; (b) numerical profiles; (c) experimental profiles (multi-color) and digital profiles (black on white) [13]. 


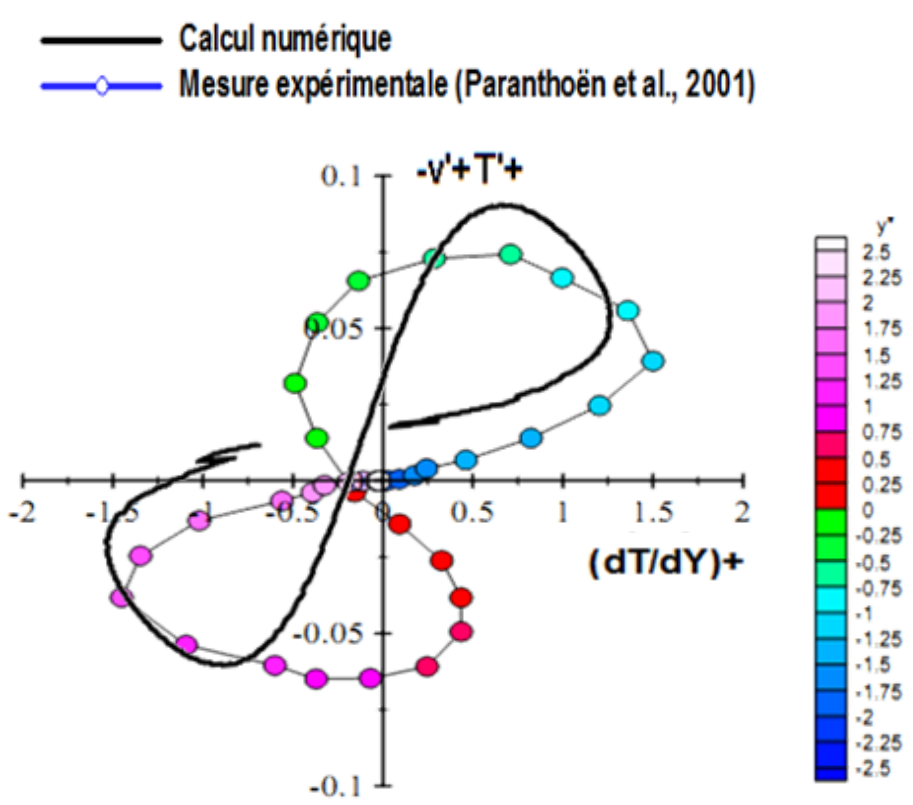

Fig. 17 Comparison of the profiles of the transverse flux of heat as a function of the transverse gradient of mean temperature $-v^{++} \mathbf{T}^{\prime+}=\mathbf{f}\left((\mathrm{dT} / \mathrm{dY})^{+}\right)$to $\mathrm{X}^{+}=9[13]$.

appears more clearly in Fig. 17 where we have plotted $\left.-\left\langle\mathrm{v}^{\prime T}\right\rangle^{\prime}\right\rangle^{+}$as a function of $\langle\partial \Delta \mathrm{T} / \partial \mathrm{y}\rangle^{+}$.

\subsection{Comparison of the Profiles of the Transversal Flux} of Heat as a Function of the Mean Transverse Temperature Gradient $-v{ }^{{ }^{+}} T^{{ }^{+}}=f\left((d T / d Y){ }^{+}\right)$ Numerical and Experimental at $X^{+}=8, X^{+}=9, X^{+}$ $=11, X^{+}=15, X^{+}=23$ and $\operatorname{Re}=63$

The experimental points obtained for $\Delta \mathrm{X}^{+}=2$ and 6 are located on two loops that intersect at the origin. The points belonging to quadrants 2 and 4 and, synonymous with counter-gradient are all located in the central zone of the whirlpool alley. At the position $\mathrm{X}^{+}=9$, the two profiles shown below have the same graphical appearance. These two graphs each have two curvatures that curl at the beginning. In addition, their maximum and minimum values are approximately the same.

Indeed, each of them is looped at the origin of the reference and, thus, we have a positive and negative loop: which reflects the existence of zones of thermal counter-flux. However, the curve obtained numerically illustrates a certain discontinuity at the level of the negative loop which is not the case with the experimental curve of Paranthoën et al. [13, 15] obtained in 2001. If the gradient model was valid, we could express the transverse flow of heat in the form $\left\langle\mathrm{v}^{\prime} \mathrm{T}\right\rangle^{\prime}{ }^{+}=-\mathrm{Dt}(\partial \Delta \mathrm{T} / \partial \mathrm{y}){ }^{+}$and the loops would be reduced to a positive slope curve passing through the origin. In the case of constant diffusivity this curve would be a straight line. We have thus demonstrated the existence of a counter-gradient situation by considering the values of the heat flux averaged over time. The results obtained show that in the central part of the thermal plume, the transverse heat flux and the average temperature transverse gradient are always of the same sign, which shows the existence of a counter-gradient region.

The different iso-value contours of velocity, isothermal and heat flux emitted by the source, in a very localized manner, show that the heat is initially preferentially convected in these two corresponding directions. This explains the existence of two maxima observed on the average temperature profiles (see Fig. 16) and positioned symmetrically with respect to the central line. From these contours, it thus appears that the wake is the result of vortices which are the cause of the existence of the zones with a gradient. 


\section{Conclusions}

From these results, it appears on the one hand that the use of ambient air cooled through an air-ground heat exchanger considerably reduces the temperature of the very hot ambient air and therefore accelerates the diffusion of heat around the solar panel PV. On the other hand, the stability of the wake is influenced by the behavior of the physical properties as a function of the temperature and the geometrical configuration considered. In addition, we have illustrated that the thermal field is strongly influenced by the geometry of the vortices aisle. The diffusion process seems to present two phases related to the filling time of the vortex alley. Moreover, in this situation where the average temperature profile is created by the heat transfer, one could rather speak in these zones with a counter-gradient of "average temperature profile with counter-flux". The counter-gradient results from a relatively simple situation where zones of the heated fluid of small dimensions (relative to the scale of the velocity field) are transported preferentially, in directions different from that of the main flow. In this case, the downstream heat flow and the average temperature profile are no longer compatible with the gradient transport model. The different comparisons made between the numerical profiles and the experimental profiles illustrate a good similarity between them. But the difference noticed is at the level of the maximum values. From the above, we can conclude that our results are validated.

\section{Acknowledgement}

The authors acknowledge the CORIA UMR 6614 CNRS University of Rouen-France, and the National Advanced School of Engineering of University of Yaoundé I, Cameroon.

\section{References}

[1] Kader Toguyeni, D. Y., and Malbila, E. 2018. "Parametric Study by Dynamic Simulation of the Influence of the Air Infiltration Rate and the Convective Thermal Transfer Coefficient on the Thermal Behavior of
Residential Buildings Built with Cut Lateritic Blocks.” Journal of Energy and Power Engineering 12: 177-85. doi: 10.17265/1934-8975/2018.04.002.

[2] Warhaft, Z. 2000. "Passive Scalars in Turbulent Flows." Annu. Rev. Fiuid Mech. 32: 203.

[3] Le Masson, S. 1991. "Contrôle de l'instabilité de Bénard Von Karman en aval d'un obstacle chauffe à faible nombre de Reynolds." Thèse de Doctorat, Université de Rouen, Mont-SaintAignan, France.

[4] Le Masson, S. 1991. "Contrôle de l'instabilité de Bénard Von Karman en aval d'un obstacle chauffe à faible nombre de Reynolds." Thèse de Doctorat, Université de Rouen, Mont-SaintAignan, France.

[5] Brajon-Socolescu, L. 1996. "Etude numérique de l'instabilité de Bénard Von Karman derrière uncylindre chauffé." Thèse de Doctorat, Université du Havre, Le Havre, France.

[6] Lecordier, J-C., Weiss, F., Dumouchel F., and Paranthoën, P. 1997. "Contrôle de la transition en aval d'un obstacle 2D au moyen d'une source de chaleur localisée dans son proche sillage." In Congrès SFT 97, Toulouse, Elsevier, 237-42.

[7] Weiss F. 1999. "Diffusion d'un scalaire passif dans le proche sillage d'un obstacle." Thèse de Doctorat, U.M.R. 6614 CNRS Université de Rouen, 76821 Mont Saint-Aignan, France.

[8] Tina, G. M., Grasso, A. D., and Gagliano, A. 2015. "Monitoring of Solar Cogenerative PVT Power Plants: Overview and a Practical Example." Sust. Energy Technol. Assess. 10: 90-101.

[9] Li, Y. 2016. "Approches analytique et expérimentale de la convection naturelle en canal vertical: Application aux double-fa cades photovoltaïques." Energie électrique. Universite de Lyon. Français. NNT: 2016LYSEI00.

[10] Ndongo, B., Lako Mbouendeu, S., and Hiregued, J. P. 2015. "Impacts socio-sanitaires et environnementaux de la gestion des eaux pluviales en milieu urbain sahélien : cas de Maroua, Cameroun." Afrique Science 11 (1): 237-42.

[11] Mihalakakou, G., Santamouris, M., Asimakopoulos, D. N., and Argiriou, A. 1995. "On the Ground Temperature below Buildings.” Solar Energy 55 (5): 355362.

[12] Benfateh Hocine. 2009. "Etude du Rafraîchissement par la Géothermie, Application à l'Habitat." Mémoire de Magister en génie Mécanique, Université de Biskra.

[13] Tagne Kaptue, B. S., Tcheukam-Toko, D., Kuitche, A., Mouangue, R., and Paranthoën, P. 2013. "Study of Turbulent Flow Downstream from a Linear Source of Heat Placed inside the Cylinder Wake." Journal of Engineering and applied Sciences 7 (5): 364-71.

[14] Fluent 6.3.26. 2006. User Manual, available at http,/www.fluent.com. 
[15] Paranthoën, P., Godard, G., and Gonzalez, M. 2001. "Diffusion a contre-gradient en aval d'une source linéaire de chaleur placée dans une allée de bénard-karman." $\mathrm{XV}^{\mathrm{ème}}$ Congrès Français de Mécanique.

[16] Rosa-Clot, M., Rosa-Clot, P., Tina, G. M., and Ventura C. 2016. "Experimental Photovoltaic-Thermal Power Plants Based on TESPI Panel.” Solar Energy 133: 305-14.

[17] Tagne Kaptue, B. S. 2012. "Dispositif de récupération d'énergie thermique et mécanique." Mémoire Brevet d'invention, OAPI Yaoundé; Procès verbal $\mathrm{N}^{\circ}$ 1201200004.

[18] Good, C., Andresen, I., and Hestnes, A. 2015. "Solar Energy for Net Zero Energy Buildings-A Comparison between Solar Thermal, PV and Photovoltaic-Thermal (PV/T) Systems." Solar Energy 122: 986-96.

[19] Paranthoën, P., Weiss, F., Corbin, F., and Lecordier, J. C. 1999. "Diffusion d'un scalaire passif dans le proche sillage d'un obstacle." U.M.R. 6614 CNRS Université de Rouen, 76821 Mont Saint-Aignan, France. 